\title{
Stellar laboratories: new Ge V and Ge VI oscillator strengths and their validation in the hot white dwarf RE 0503-289
}

\author{
T. Rauch ${ }^{1}$, K. Werner ${ }^{1}$, É. Biémont ${ }^{2,3}$, P. Quinet ${ }^{2,3}$, and J. W. Kruk ${ }^{4}$ \\ 1 Institute for Astronomy and Astrophysics, Kepler Center for Astro and Particle Physics, Eberhard Karls University, Sand 1, \\ 72076 Tübingen, Germany \\ e-mail: rauch@astro.uni-tuebingen.de \\ 2 Astrophysique et Spectroscopie, Université de Mons - UMONS, 7000 Mons, Belgium \\ 3 IPNAS, Université de Liège, Sart Tilman, 4000 Liège, Belgium \\ ${ }^{4}$ NASA Goddard Space Flight Center, Greenbelt, MD 20771, USA
}

Received 13 July 2012 / Accepted 14 August 2012

\section{ABSTRACT}

\begin{abstract}
Context. State-of-the-art spectral analysis of hot stars by means of non-LTE model-atmosphere techniques has arrived at a high level of sophistication. The analysis of high-resolution and high-S/N spectra, however, is strongly restricted by the lack of reliable atomic data for highly ionized species from intermediate-mass metals to trans-iron elements. Especially data for the latter has only been sparsely calculated. Many of their lines are identified in spectra of extremely hot, hydrogen-deficient post-AGB stars. A reliable determination of their abundances establishes crucial constraints for AGB nucleosynthesis simulations and, thus, for stellar evolutionary theory.

Aims. In a previous analysis of the UV spectrum of RE 0503-289, spectral lines of highly ionized Ga, Ge, As, Se, Kr, Mo, Sn, $\mathrm{Te}, \mathrm{I}$, and Xe were identified. Individual abundance determinations are hampered by the lack of reliable oscillator strengths. Most of these identified lines stem from Ge v. In addition, we identified Ge vi lines for the first time. We calculated Ge V and Ge VI oscillator strengths in order to reproduce the observed spectrum.

Methods. We newly calculated Ge v and Ge VI oscillator strengths to consider their radiative and collisional bound-bound transitions in detail in our non-LTE stellar-atmosphere models for the analysis of the Ge IV-VI spectrum exhibited in high-resolution and high-S/N FUV (FUSE) and UV (ORFEUS/BEFS, IUE) observations of RE 0503-289.

Results. In the UV spectrum of RE 0503-289, we identify four Ge IV, $37 \mathrm{Ge} \mathrm{V}$, and seven Ge VI lines. Most of these lines are identified for the first time in any star. We can reproduce almost all Ge IV, Ge V, and Ge VI lines in the observed spectrum of RE 0503-289 $\left(T_{\text {eff }}=70 \mathrm{kK}, \log g=7.5\right)$ at $\log \mathrm{Ge}=-3.8 \pm 0.3$ (mass fraction, about 650 times solar). The Ge IV/v/VI ionization equilibrium, that is a very sensitive $T_{\text {eff }}$ indicator, is reproduced well.

Conclusions. Reliable measurements and calculations of atomic data are a prerequisite for stellar-atmosphere modeling. Our oscillator-strength calculations have allowed, for the first time, Ge v and Ge vi lines to be successfully reproduced in a white dwarf's (RE 0503-289) spectrum and to determine its photospheric Ge abundance.
\end{abstract}

Key words. atomic data - line: identification - stars: abundances - stars: individual: RE0503-289 - white dwarfs virtual observatory tools

\section{Introduction}

Any model-atmosphere calculation is strongly dependent on the available and reliable atomic data, which is a crucial input. Especially for highly ionized species and higher atomic mass, published data becomes rather sparse. A close inspection of the UV spectrum of the hot white dwarf RE 0503-289 by Werner et al. (2012) has shown that a large number of the hitherto unidentified observed spectral lines stem from trans-iron elements, namely Ga, Ge, As, Se, Mo, Sn, Te, and I.

Identification of the respective spectral lines is fairly straightforward because atomic databases like NIST $^{1}$ and

\footnotetext{
* Based on observations made with the NASA-CNES-CSA Far Ultraviolet Spectroscopic Explorer.

$\star \star$ Figures 4-6 and Tables 1, 3 are available in electronic form at http: //www . aanda.org

$\star \star \star$ Tables 2 and 4 are only available at the CDS via anonymous ftp to cdsarc.u-strasbg.fr (130.79.128.5) or via

http://cdsarc.u-strasbg.fr/viz-bin/qcat?]/A+A/546/A55

1 http://www.nist.gov/pml/data/asd.cfm
}

Kelly's database ${ }^{2}$ have partly included the strongest lines of these elements with accurate wavelengths, whereas a quantitative analysis requires adequate spectral modeling. This is hampered by the fact that line strengths for trans-iron elements, when available at all, are relative intensities measured from emission line spectra. Exploratory atmosphere models that are based on the LTE assumption to calculate occupation numbers of the atomic levels of an ion and on $\log g f$ values scaled to match the relative line strengths may show that the line identifications are correct. A reliable abundance analysis, however, is impossible owing to the lack of measured or calculated transition probabilities.

The line identification was demonstrated by Werner et al. (2012) in the case of RE0503-289. It is a hot $\left(T_{\mathrm{eff}}=70 \mathrm{kK}\right.$, $\log g=7.5$ ), helium-rich DO-type white dwarf (WD 0501-289, $\alpha_{2000}=05^{\mathrm{h}} 03^{\mathrm{m}} 55^{\mathrm{s}} .513, \delta_{2000}=-28^{\circ} 54^{\prime} 34^{\prime \prime} .57$ ), which is wellsuited to UV spectroscopy because its spectrum is only slightly contaminated by interstellar absorption. Werner et al. (2012) performed an abundance analysis of $\mathrm{Kr}$ and $\mathrm{Xe}$ where level energies

2 http://www.cfa.harvard.edu/ampcgi/kelly.pl 


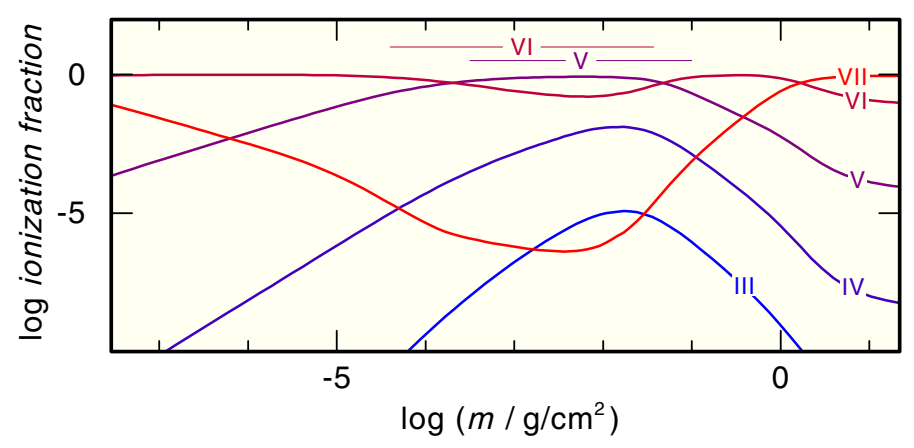

Fig. 1. Ionization fractions of Ge III-VII. The formation depths of the Ge $\mathrm{V}$ and Ge VI line cores are marked at the top.

and oscillator strengths of $\mathrm{Kr}$ VI, Kr viI, Xe vI, and Xe viI were already published. They determined $\log \mathrm{Kr}=-4.3 \pm 0.5$ and $\log \mathrm{Xe}=-4.2 \pm 0.6$ (mass fractions) and identified a variety of lines of the other trans-iron elements mentioned above.

Only level energies and (partly) relative line strengths were accessible for $\mathrm{Ge}$. A test calculation of an $\mathrm{H}+\mathrm{Ge}$-composed model atmosphere with the relevant parameters $\left(T_{\text {eff }}=70 \mathrm{kK}\right.$, $\log g=7.5), \log \mathrm{Ge}=-4$ ) shows that Ge $\mathrm{v}$ and Ge vi are dominant in the line-forming region (Fig. 1). Consequently, we calculated transition probabilities anew for Ge v and Ge vi (Sect. 2). In Sect. 3, we briefly introduce the available observed spectra, which are used for our Ge abundance analysis of RE 0503-289 that is presented in Sect. 4. In Sect. 5 we re-assess the effective temperature of RE 0503-289 based on the C III / C IV ionization balance. Results and conclusions are summarized in Sect. 6.

\section{Transition probabilities in $\mathrm{Ge} v$ and $\mathrm{Ge}$ vı}

There are not very many transition probabilities or oscillator strengths in $\mathrm{Ge} v$ and $\mathrm{Ge}$ vI ions. In Ge v, some pioneering $\mathrm{HFR}^{3}$ and MCDF$^{4}$ (Grant \& McKenzie 1980; Grant et al. 1980) results were reported by Quinet \& Biémont $(1990,1991)$ but the work of these authors was limited to $3 d-4 p$ and $3 d-4 f$ transitions in nickel-like ions ( $\mathrm{Ge} \mathrm{V}-\mathrm{Pb} \mathrm{LV})$. More recent work comes from Safronova and co-workers (Safronova et al. 2000; Hamasha et al. 2004; Safronova et al. 2006a,b; Safronova \& Safronova 2006), who performed relativistic many-body calculations for multipole transitions (E1, M1, E2, M2, E3, M3) originating in the ground states.

In Ge vI, the available results are limited to forbidden transitions in $3 \mathrm{~d}$ and $3 \mathrm{~d}^{9}$ configurations (Biémont \& Hansen 1989) and to the theoretical investigation of electric dipole transitions between $3 d^{9}$ and $d^{8} p$ configurations in zinc, gallium, and germanium ions (Jucys et al. 1968).

As there is no uniform set of oscillator strengths available for all the transitions of Ge ions observed in the present work, we decided to perform the relevant calculations. The method adopted here is the relativistic Hartree-Fock approach frequently referred to in the literature as the HFR or Cowan's method (Cowan 1981).

For Gev, configuration interaction has been considered among the configurations $3 \mathrm{~d}^{10}, 3 \mathrm{~d}^{9} n \mathrm{~s}(n=4-7), 3 \mathrm{~d}^{9} n \mathrm{~d}(n=4-7)$, $3 \mathrm{~d}^{8} 4 \mathrm{~s}^{2}, 3 \mathrm{~d}^{8} 4 \mathrm{p}^{2}, 3 \mathrm{~d}^{8} 4 \mathrm{~d}^{2}, 3 \mathrm{~d}^{8} 4 \mathrm{f}^{2}, 3 \mathrm{~d}^{8} 4 \mathrm{~s} n \mathrm{~s}(n=5-7), 3 \mathrm{~d}^{8} 4 \mathrm{~s} n \mathrm{~d}(n=$ $4-7)$, and $3 \mathrm{~d}^{8} 4 \mathrm{p} 4 \mathrm{f}$ for the even parity, and $3 \mathrm{~d}^{9} n \mathrm{p}(n=4-7), 3 \mathrm{~d}^{9} n \mathrm{f}$ $(n=4-7), 3 \mathrm{~d}^{8} 4 \mathrm{~s} n \mathrm{p}(n=4-7), 3 \mathrm{~d}^{8} 4 \mathrm{~s} n \mathrm{f}(n=4-7)$, and $3 \mathrm{~d}^{8} 4 \mathrm{p} 4 \mathrm{~d}$ for the odd parity. Using experimental energy levels reported by

\footnotetext{
3 Hartree-Fock with relativistic corrections.

4 Multi-Configuration Dirac-Fock.
}

Sugar \& Musgrove (1993) and Churilov et al. (1997), the radial integrals (average energies, Slater integrals, spin-orbit parameters) of $3 \mathrm{~d}^{10}, 3 \mathrm{~d}^{9} n \mathrm{~s}(n=4-7), 3 \mathrm{~d}^{9} n \mathrm{p}(n=4-6), 3 \mathrm{~d}^{9} n \mathrm{~d}(n=4,5)$, $3 d^{9} 4 \mathrm{f}$ and $3 d^{8} 4 \mathrm{~s} 4 \mathrm{p}$ were optimized by a well-established leastsquares fitting procedure. In this process, the $3 \mathrm{~d}^{9} 4 \mathrm{~d}{ }^{1} \mathrm{~S}_{0}$ level at $493765.5 \mathrm{~cm}^{-1}$ (Sugar \& Musgrove 1993) and the $3 \mathrm{~d}^{8} 4 \mathrm{~s} 4 \mathrm{p}$ $(J=1)$ level at $673405 \mathrm{~cm}^{-1}$ (Churilov et al. 1997), affected by larger uncertainties, were not considered.

For Ge vI, the configurations included in the HFR model were $3 d^{9}, 3 d^{8} 4 s, 3 d^{8} 5 s, 3 d^{8} 4 d, 3 d^{8} 5 d, 3 d^{7} 4 s^{2}, 3 d^{7} 4 p^{2}, 3 d^{7} 4 d^{2}$, $3 d^{7} 4 f^{2}, 3 d^{7} 4 s 5 s, 3 d^{7} 4 s 4 d$, and $3 d^{7} 4 s 5 d$ for the even parity and $3 d^{8} 4 p, 3 d^{8} 5 p, 3 d^{8} 4 f, 3 d^{8} 5 f, 3 d^{7} 4 s 4 p, 3 d^{7} 4 s 5 p, 3 d^{7} 4 s 4 f, 3 d^{7} 4 s 5 f$, and $3 d^{7} 4 p 4 d$ for the odd parity. In this case, the semi-empirical process was performed to optimize the radial integrals corresponding to $3 d^{9}, 3 d^{8} 4 s$, and $3 d^{8} 4 p$ configurations using the experimental levels reported by Sugar \& Musgrove (1993). The $3 d^{9} 4 \mathrm{f}$ levels were excluded from the fit because many of these were found to be mixed with experimentally unknown levels belonging notably to the $3 \mathrm{~d}^{9} 5 \mathrm{p}$ configuration.

The experimental and calculated energy levels for Ge v, expressed in $\mathrm{cm}^{-1}$, are reported in Table 1 which also shows the differences between both sets of results $(\Delta E)$ and, in the last column, the percentage composition in LS-coupling (only the first three components over $5 \%$ are given). This last piece of information is useful because oscillator strengths for transitions connecting strongly perturbed levels are more sensitive to configuration interaction effects.

The calculated HFR oscillator strengths on a logarithmic scale $(\log g f)$ and transition probabilities $\left(g A\right.$, in $\left.\mathrm{s}^{-1}\right)$ for $\mathrm{Ge} \mathrm{v}$ are reported in Table 2 with the corresponding wavelengths (in $\AA$ ) and energy levels (in $\mathrm{cm}^{-1}$ ). In the last column, we give the cancellation factor CF as defined by Cowan (1981). Low values of this factor indicate strong cancellation effects in the calculations. The corresponding transition probabilities could be very inaccurate so need to be considered with some care. It does appear, however, from the last column of the table that very few transitions are affected by such effects.

The experimental and calculated energy levels for Ge VI appear in Table 3 and the corresponding calculated HFR oscillator strengths and transition probabilities are reported in Table 4. Here too, very few transitions are affected by cancellation effects so that for most of the transitions, the $f$ values should be reliable.

\section{Observations}

For our analysis, we mainly use the FUSE spectrum of RE 0503-289 that is described in detail by Werner et al. (2012). In addition, we use UV spectra that were obtained with ORFEUS ${ }^{5} / \mathrm{BEFS}^{6}$, ORFEUS/GHRS ${ }^{7}$ and $\mathrm{IUE}^{8}$. The BEFS spectrum (909-1222 $\AA$ ) is co-added from five observations (ObsIds: BEFS2003, BEFS2126, BEFS2128, BEFS2133, BEFS2173; with a total observation time of $6826 \mathrm{~s})$. The GHRS spectrum (1228-1275 $\AA$, 1339$1375 \AA, 1610-1655 \AA)$ is co-added from eight observations (ObsIds: Z3GM0204T, Z3GM0205T, Z3JU0104T, Z3JU0107T, Z3JU0108T, Z3JU0109T, Z3JU010AT, Z3JU010BT; $5155 \mathrm{~s}$ ). The IUE spectrum (1153-1947 $\AA$ ) is the co-added spectrum (ObsIds: SWP46428, SWP49788, SWP52796, SWP52803;

\footnotetext{
5 Orbiting Retrievable Far and Extreme Ultraviolet Spectrometer.

6 Berkeley Extreme and Far-UV Spectrometer.

7 Goddard High-Resolution Spectrograph.

8 International Ultraviolet Explorer.
} 
Table 5. Statistics of the Ge model atom used in our calculations.

\begin{tabular}{lcllcccc}
\hline \hline \multirow{2}{*}{ Ion } & \multicolumn{2}{c}{ Levels } & & \multicolumn{3}{c}{ Line transitions } \\
\cline { 2 - 3 } \cline { 5 - 7 } & NLTE & LTE & & total & known $f$ & unknown $f$ \\
\hline III & 14 & 2 & & 0 & & \\
IV & 8 & 1 & & 8 & 8 & \\
V & 85 & 0 & & 1345 & 878 & 467 \\
VI & 36 & 0 & & 235 & 160 & 75 \\
VII & 1 & 0 & & 0 & & \\
\hline
\end{tabular}

$136193 \mathrm{~s}$ ) provided by the IUE NEWSIPS data base ${ }^{9}$ (Holberg et al. 1998).

Optical spectra were taken in the framework of the SPY ${ }^{10}$ project (Napiwotzki et al. 2001, 2003) with UVES $^{11}$ at ESO's ${ }^{12}$ VLT $^{13}$.

\section{The photospheric Ge abundance in RE 0503-289}

Ge v and Ge vi are the dominant ionization stages in the lineforming region of RE 0503-289 (Fig. 1). Thus, we constructed a Ge III-VII model atom (Table 5, Fig. 2). We used level energies from NIST for all ions. For Ge IV, we considered the oscillator strengths of Nath Dutta \& Majumder (2011) and, where missing, approximated values from the isoelectronic C IV. Ge v and Ge vi include our newly calculated oscillator strengths (Sect. 2). Analogously to Werner et al. (2012) in the case of Kr and Xe, the unknown $f$ values (Table 5) of these two ions were set to $10^{-4}$ within a spin and to $10^{-6}$ otherwise. Test calculations have shown that the Ge line profiles in the UV do not change when we set $f=0$ for these lines. Photoionization rates were computed with hydrogen-like crosssections. Electron collisional excitation and ionization rates were evaluated with the usual approximation formulae following van Regemorter (1962) and Seaton (1962), respectively. This enabled us to build on the HeCNOKrXe models for RE 0503-289 described by Werner et al. (2012) and to consider Ge opacities as well as iron-group opacities (elements $\mathrm{Ca}-\mathrm{Ni}$, own determination of upper abundance limits) in addition. Compared to Werner et al. (2012), we reduced the $\mathrm{N}$ abundance to match the $\mathrm{N}_{\text {IV }} 2 \mathrm{p}^{3} \mathrm{P}^{\mathrm{o}}-2 \mathrm{p}^{2}{ }^{3} \mathrm{P}$ multiplet (921-924 $\mathrm{A}$, Fig. 3).

We used the Tübingen Model-Atmosphere Package (TMAP $^{14}$ Werner et al. 2003) to calculate state-of-the-art, plane-parallel, chemically homogeneous model atmospheres in hydrostatic and radiative equilibrium. The considered model atoms are those that are provided via the Tübingen Model-Atom Database (TMAD ${ }^{15}$, Rauch \& Deetjen 2003).

We compared the available UV spectra of RE0503-289 (Sect.3) with our TMAP model (and wavelength positions given by NIST and Kelly's database) in order to identify Ge lines. The line lists in that energy region, especially for the highly ionized trans-iron elements that are encountered, are rather incomplete, and thus, lines that are not considered in the models may contribute to the assumed isolated Ge lines. Gav $\lambda \lambda 1054.560,1069.450 \AA$ are two examples (Fig. 3). The consideration of $\mathrm{Ga}$ in the model-atmosphere calculation would

\footnotetext{
9 http://vega.lpl.arizona.edu/newsips/

${ }^{10}$ ESO SN Ia Progenitor surveY.

${ }^{11}$ Ultraviolet and Visual Echelle Spectrograph.

12 http://www . eso.org/public/

${ }_{13}$ Very Large Telescope.

${ }^{14}$ http://astro.uni-tuebingen.de/ TMAP

${ }^{15}$ http://astro.uni-tuebingen.de/ TMAD
}

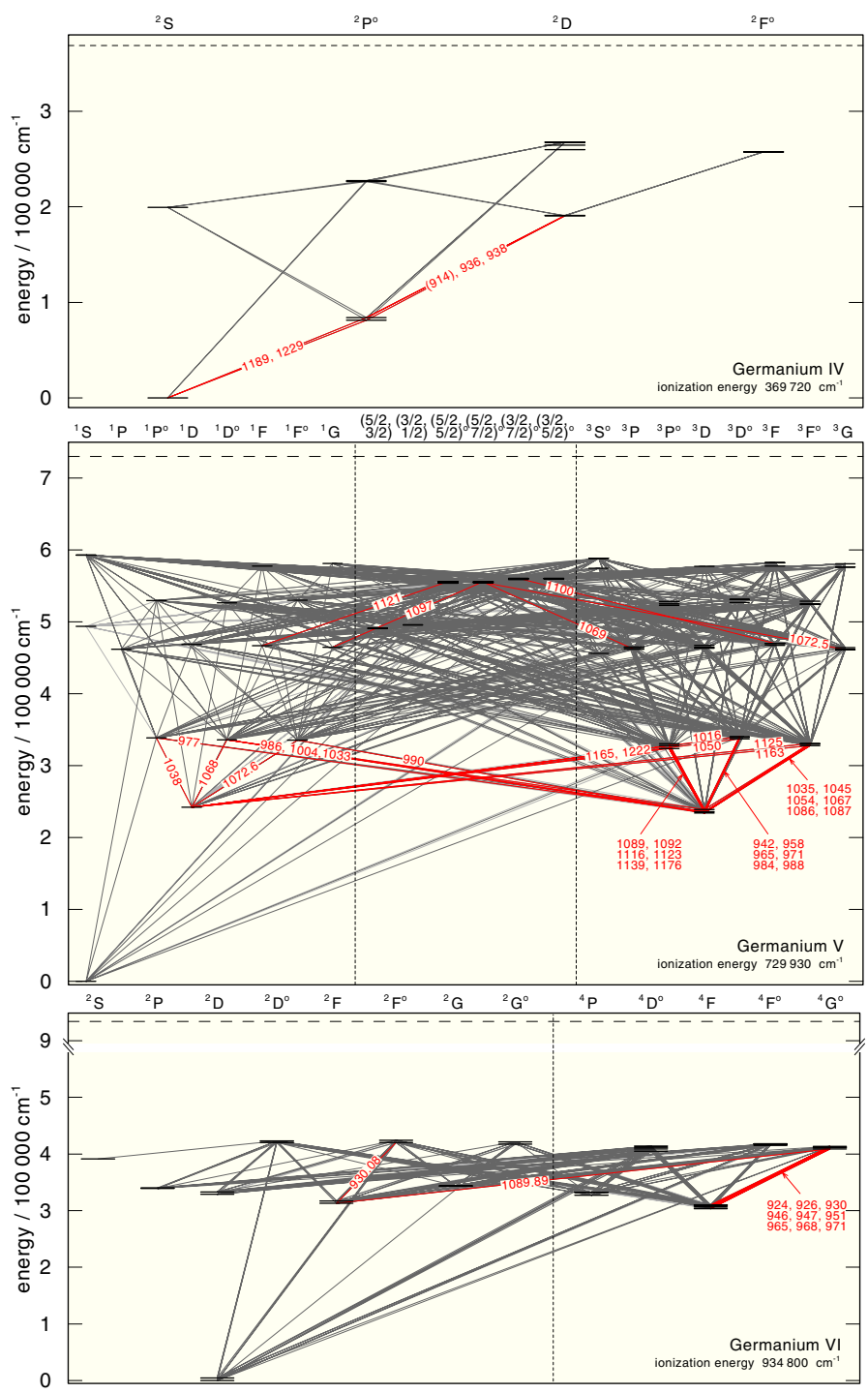

Fig. 2. Grotrian diagram of our Ge IV (top), Ge v (middle), and Ge VI (bottom) model ions. Thick black and thin gray lines represent radiative transitions with known and unknown $f$ values, respectively. The identified lines (red) are labeled with their respective wavelengths in $\AA$.

improve the fit of the blends with Ge v $\lambda \lambda 1054.588,1069.419 \AA$. However, we identify four Ge Iv, $37 \mathrm{Ge} v$, and six Ge vi lines (Table 6). All Ge IV and Ge v lines are in general reproduced in both strength and width by our model simultaneously at $\log \mathrm{Ge}=$ $-3.81 \pm 0.3$ (Fig. 3). There is only one line, Ge $v \lambda 1123.744 \AA$, that is much too strong in our model. The reason is unknown. The Ge vi lines are weak in our model and just emerge from the noise in the FUSE observation, but they do agree. Ge vi $\lambda \lambda 986.721,1039.890 \AA$ are too weak to reproduce the observed absorption features, most likely due to unknown blends at their positions that are not considered in the model. However, the large number of identified $\mathrm{Ge}$ lines and their modeling give convincing evidence that our model and the determined Ge abundance are realistic.

\section{Effective temperature and surface gravity of RE 0503-289}

Both $T_{\text {eff }}$ and $\log g$ were adopted from Werner et al. (2012) for this analysis. Figure 3 shows that the $C_{\text {III }}$ multiplet $2 \mathrm{p}^{3} \mathrm{P}^{\mathrm{o}}-$ $2 \mathrm{p}^{2}{ }^{3} \mathrm{P}(1174-1176 \AA)$ in our model is too weak. Since an 


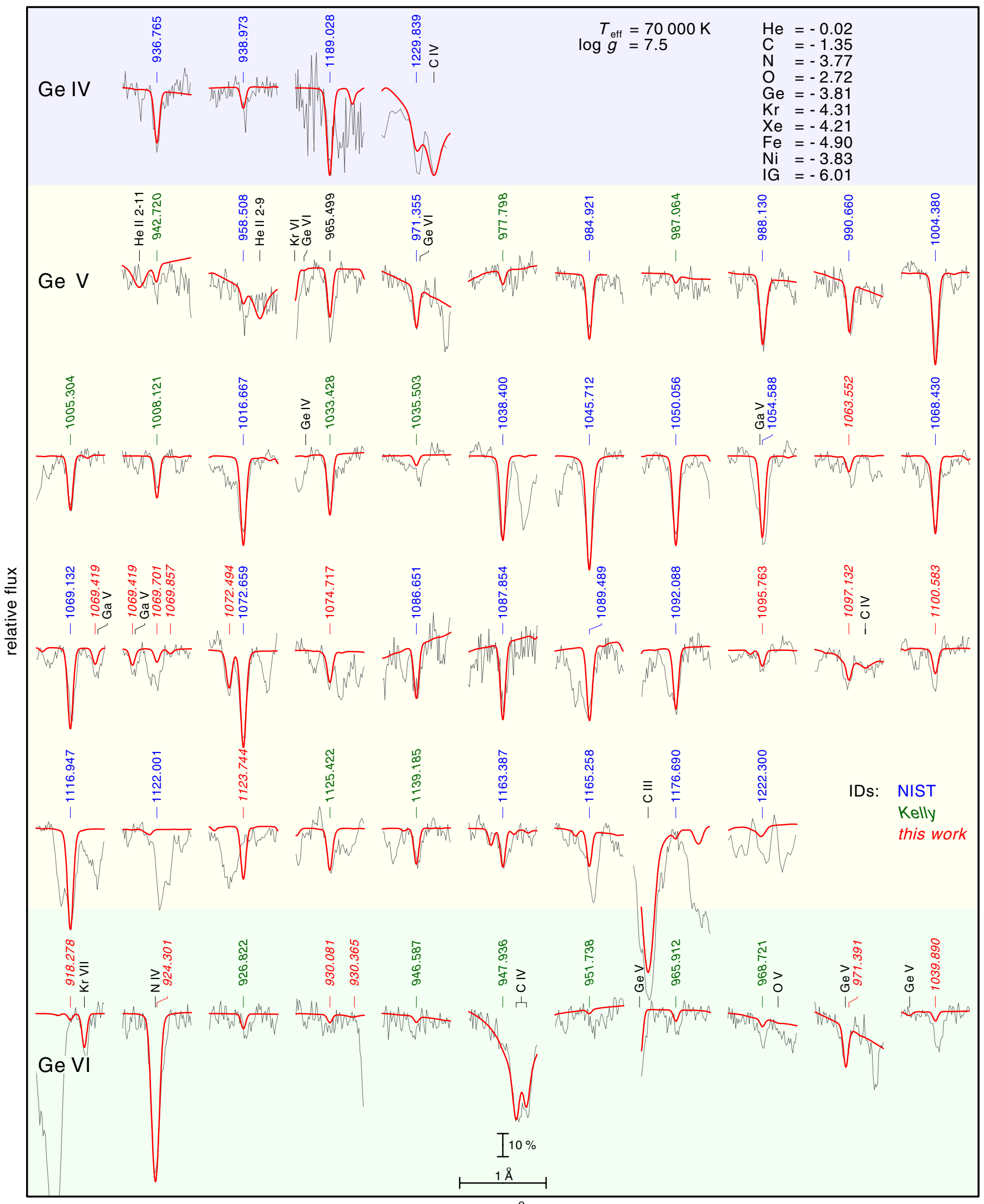

$\Delta \lambda / \AA$

Fig. 3. Ge IV (top), Ge v, and Ge VI (bottom) lines in FUSE, ORFEUS/BEFS (Ge IV $\lambda 1189 \AA$ ), and IUE (Ge v $\lambda 1222 \AA$, Ge IV $\lambda 1229 \AA$ ) observations compared with a $T_{\text {eff }}=70 \mathrm{kK} / \log g=7.5$ TMAP model. The abundances (top right) are logarithmic mass fractions. IG denotes a generic model atom (Rauch \& Deetjen 2003), which comprises Ca, Sc, Ti, V, Cr, Mn, and Co. The synthetic spectra a convolved with a Gaussian of $0.05 \AA$ ( $F W H M, 0.1 \AA$ for the IUE comparison) to match the instrument resolution. A radial-velocity shift of $v_{\text {rad }}=23 \mathrm{~km} \mathrm{~s}^{-1}$ is applied to the observation. 
T. Rauch et al.: Stellar laboratories: new Ge V and Ge VI oscillator strengths

Table 6. Identified Ge lines in the UV spectrum of RE 0503-289.

\begin{tabular}{|c|c|c|c|c|c|c|}
\hline Ion & Lower level & Upper level & $f$ value & \multicolumn{2}{|c|}{ Wavelength / ̊ } & Comment \\
\hline \multirow[t]{4}{*}{ Ge IV } & $4 p^{2} \mathrm{P}_{3 / 2}^{\mathrm{o}}$ & $4 d^{2} D_{5 / 2}$ & $8.91 \mathrm{E}-01$ & 936 & 765 & \\
\hline & $4 p^{2} \mathrm{P}_{3 / 2}^{\mathrm{o} / 2}$ & $4 d^{2} D_{3 / 2}^{5 / 2}$ & $9.89 \mathrm{E}-02$ & 938 & 973 & \\
\hline & $4 \mathrm{~s}^{2} \mathrm{~S}_{1 / 2}^{3 / 2}$ & $4 p^{2} \mathrm{P}_{3 / 2}^{3 / 2}$ & $5.54 \mathrm{E}-01$ & 1189 & 028 & \\
\hline & $4 s^{2} S_{1 / 2}^{1 / 2}$ & $4 \mathrm{p}^{2} \mathrm{P}_{1 / 2}^{\mathrm{o} / 2}$ & $2.66 \mathrm{E}-01$ & 1229 & 839 & \\
\hline \multirow[t]{44}{*}{ Ge V } & $4 s^{3} D_{3}$ & $4 p^{3} D_{2}^{o}$ & $8.22 \mathrm{E}-03$ & 942 & 720 & \\
\hline & $4 s^{3} \mathrm{D}_{2}^{3}$ & $4 \mathrm{p}^{3} \mathrm{D}^{\mathrm{o}}$ & $3.17 \mathrm{E}-02$ & 958 & 508 & \\
\hline & $4 s^{3} \mathrm{D}_{2}^{2}$ & $4 \mathrm{p}^{3} \mathrm{D}_{1}^{\mathrm{o}}$ & $3.56 \mathrm{E}-02$ & 965 & 499 & \\
\hline & $4 s^{3} \mathrm{D}_{3}^{2}$ & $4 p^{3} D_{3}^{o}$ & $1.22 \mathrm{E}-01$ & 971 & 355 & \\
\hline & $4 s^{3} D_{2}^{3}$ & $4 p^{1} \mathrm{P}_{1}^{\mathrm{o}}$ & $3.56 \mathrm{E}-03$ & 977 & 798 & \multirow[t]{2}{*}{ Kelly wavelength } \\
\hline & $4 s^{3} \mathrm{D}_{1}^{2}$ & $4 \mathrm{p}^{3} \mathrm{D}^{\mathrm{o}}$ & $1.08 \mathrm{E}-01$ & 984 & 921 & \\
\hline & $4 s^{3} D_{3}^{1}$ & $4 \mathrm{p}^{1} \mathrm{D}^{\mathrm{o}}$ & $1.13 \mathrm{E}-03$ & 987 & 064 & \multirow[t]{3}{*}{ Kelly wavelength } \\
\hline & $4 s^{3} \mathrm{D}_{2}^{3}$ & $4 \mathrm{p}^{3} \mathrm{D}^{\mathrm{o}}$ & $1.00 \mathrm{E}-01$ & 988 & 130 & \\
\hline & $4 s^{3} \mathrm{D}_{3}^{2}$ & $4 p^{1} F_{3}^{3}$ & $1.13 \mathrm{E}-01$ & 990 & 660 & \\
\hline & $4 s^{3} D_{2}^{3}$ & $4 p^{1} D_{2}^{3}$ & $1.70 \mathrm{E}-01$ & 1004 & 380 & NIST wavelength \\
\hline & $4 s^{3} D^{2}$ & $4 p^{1} \mathrm{P}^{\mathrm{o}}$ & $5.41 \mathrm{E}-02$ & 1005 & 304 & \multirow[t]{3}{*}{ Kelly wavelength } \\
\hline & $4 s^{3} \mathrm{D}_{2}^{1}$ & $4 \mathrm{p}^{1} \mathrm{~F}_{3}^{1}$ & $1.21 \mathrm{E}-02$ & 1008 & 121 & \\
\hline & $4 \mathrm{~s}^{1} \mathrm{D}_{2}$ & $4 p^{3} D_{2}^{3}$ & $1.95 \mathrm{E}-01$ & 1016 & 667 & \\
\hline & $4 s^{3} \mathrm{D}_{1}^{2}$ & $4 p^{1} D_{2}^{0}$ & $6.96 \mathrm{E}-02$ & 1033 & 428 & \multirow[t]{2}{*}{ Kelly wavelength } \\
\hline & $4 s^{3} D_{3}$ & $4 p^{3} \mathrm{~F}_{2}^{\mathrm{o}}$ & $1.01 \mathrm{E}-03$ & 1035 & 503 & \\
\hline & $4 \mathrm{~s}^{1} \mathrm{D}_{2}^{3}$ & $4 \mathrm{p}^{1} \mathrm{P}_{1}^{\mathrm{o}}$ & $1.45 \mathrm{E}-01$ & 1038 & 400 & \multirow[t]{5}{*}{ NIST wavelength } \\
\hline & $4 s^{3} \mathrm{D}_{3}$ & $4 \mathrm{p}^{3} \mathrm{~F}_{4}^{\mathrm{o}}$ & 3.94E-01 & 1045 & 712 & \\
\hline & $4 \mathrm{~s}^{1} \mathrm{D}_{2}$ & $4 \mathrm{p}^{3} \mathrm{D}_{3}^{\mathrm{o}}$ & $1.56 \mathrm{E}-01$ & 1050 & 056 & \\
\hline & $4 s^{3} \mathrm{D}_{2}^{2}$ & $4 \mathrm{p}^{3} \mathrm{~F}_{2}^{\mathrm{o}}$ & 8.93E-02 & 1054 & 588 & \\
\hline & $4 d^{3} P_{1}^{2}$ & $4 \mathrm{f}^{5} \mathrm{~F}_{2}^{\mathrm{o}}$ & 8.57E-01 & 1063 & 552 & \\
\hline & $4 s^{1} D_{2}$ & $4 p^{1} D_{2}^{o}$ & 8.73E-02 & 1068 & 430 & \multirow{16}{*}{$\begin{array}{l}\text { NIST wavelength } \\
\text { NIST wavelength }\end{array}$} \\
\hline & $4 s^{3} D_{3}^{2}$ & $4 p^{3} F_{3}^{2}$ & $6.53 \mathrm{E}-02$ & 1069 & 132 & \\
\hline & $4 d^{3} P_{2}^{3}$ & $4 f^{3}$ & $5.02 \mathrm{E}-01$ & 1069 & 419 & \\
\hline & $4 d^{1} P_{1}^{2}$ & $4 \mathrm{f}$ & $6.07 \mathrm{E}-01$ & 1069 & 701 & \\
\hline & $4 d^{3} P_{2}$ & $4 f$ & $1.10 \mathrm{E}-01$ & 1069 & 857 & \\
\hline & $4 d^{3} G_{5}^{2}$ & 4f & $9.97 \mathrm{E}-01$ & 1072 & 494 & \\
\hline & $4 \mathrm{~s}^{1} \mathrm{D}_{2}^{\mathrm{s}}$ & $4 \mathrm{p}^{1} \mathrm{~F}_{3}^{\mathrm{o}}$ & $2.52 \mathrm{E}-01$ & 1072 & 659 & \\
\hline & $4 d^{3} G_{4}^{2}$ & $4 \mathrm{f}^{3}$ & $9.68 \mathrm{E}-01$ & 1074 & 717 & \\
\hline & $4 s^{3} D_{1}^{4}$ & $4 p^{3} \mathrm{~F}_{2}^{o}$ & $3.18 \mathrm{E}-01$ & 1086 & 651 & \\
\hline & $4 s^{3} D_{2}^{1}$ & $4 \mathrm{p}^{3} \mathrm{~F}_{3}^{\mathrm{o}}$ & 3.03E-01 & 1087 & 854 & \\
\hline & $4 s^{3} D_{2}^{2}$ & $4 \mathrm{p}^{3} \mathrm{P}_{1}^{\mathrm{o}}$ & $1.42 \mathrm{E}-01$ & 1089 & 489 & \\
\hline & $4 s^{3} D_{1}^{2}$ & $4 \mathrm{p}^{3} \mathrm{P}_{0}^{\mathrm{o}}$ & $1.01 \mathrm{E}-01$ & 1092 & 088 & \\
\hline & $4 d^{3} G_{3}^{1}$ & $4 \mathrm{f}^{5} \mathrm{D}_{3}^{\mathrm{o}}$ & $1.53 \mathrm{E}-02$ & 1095 & 763 & \\
\hline & $4 d^{1} G_{4}$ & $4 \mathrm{f}$ & 7.69E-01 & 1097 & 132 & \\
\hline & $4 d^{3} F_{3}$ & $4 \mathrm{f}$ & $9.01 \mathrm{E}-01$ & 1100 & 583 & \\
\hline & $4 s^{3} D_{3}^{3}$ & $4 \mathrm{p}^{3} \mathrm{P}_{2}^{\mathrm{o}}$ & $1.97 \mathrm{E}-01$ & 1116 & 947 & \\
\hline & $4 d^{1} F_{3}^{3}$ & $4 \mathrm{f}$ & $9.44 \mathrm{E}-02$ & 1122 & 001 & \multirow[t]{6}{*}{ NIST wavelength, very weak } \\
\hline & $4 s^{3} D_{1}^{3}$ & $4 \mathrm{p}^{3} \mathrm{P}_{1}^{\mathrm{o}}$ & $3.83 \mathrm{E}-02$ & 1123 & 744 & \\
\hline & $4 \mathrm{~s}^{1} \mathrm{D}_{2}$ & $4 \mathrm{p}^{3} \mathrm{~F}_{2}^{\mathrm{o}}$ & $1.29 \mathrm{E}-02$ & 1125 & 422 & \\
\hline & $4 s^{3} \mathrm{D}_{2}^{2}$ & $4 \mathrm{p}^{3} \mathrm{P}_{2}^{\mathrm{o}}$ & $9.14 \mathrm{E}-03$ & 1139 & 185 & \\
\hline & $4 \mathrm{~s}^{1} \mathrm{D}_{2}^{2}$ & $4 \mathrm{p}^{3} \mathrm{~F}_{3}^{\mathrm{o}}$ & $1.29 \mathrm{E}-02$ & 1163 & 387 & \\
\hline & $4 \mathrm{~s}^{1} \mathrm{D}_{2}^{2}$ & $4 \mathrm{p}^{3} \mathrm{P}_{1}^{\mathrm{o}}$ & $1.48 \mathrm{E}-02$ & 1165 & 258 & \\
\hline & $4 s^{3} \mathrm{D}_{1}^{2}$ & $4 \mathrm{p}^{3} \mathrm{P}_{2}^{\mathrm{o}}$ & $2.06 \mathrm{E}-03$ & 1176 & 690 & \multirow{2}{*}{$\mathrm{C}$ III blend } \\
\hline & $4 \mathrm{~s}^{1} \mathrm{D}_{2}$ & $4 \mathrm{p}^{3} \mathrm{P}_{2}^{\mathrm{o}}$ & 4.91E-03 & 1222 & 300 & \\
\hline \multirow[t]{12}{*}{$\overline{\text { Ge VI }}$} & $4 \mathrm{~s}^{4} \mathrm{~F}_{7 / 2}$ & $4 p^{4} G_{9 / 2}^{o}$ & $2.34 \mathrm{E}-04$ & 918 & 278 & \multirow{12}{*}{$\mathrm{N}$ IV blend } \\
\hline & $4 s^{4} F_{9 / 2}$ & $4 p^{4} G_{7 / 2}^{o}$ & $2.34 \mathrm{E}-04$ & 924 & 301 & \\
\hline & $4 s^{4} F_{9 / 2}$ & $4 p^{4} G_{11 / 2}^{o}$ & $3.63 \mathrm{E}-01$ & 926 & 822 & \\
\hline & $4 s^{2} F_{7 / 2}^{9 / 2}$ & $4 p^{2} F_{7 / 2}^{o}$ & $2.43 \mathrm{E}-01$ & 930 & 081 & \\
\hline & $4 s{ }^{4} F_{7 / 2}$ & $4 p^{4} G_{5 / 2}^{o}$ & 8.07E-04 & 930 & 365 & \\
\hline & $4 s^{4} F_{7 / 2}$ & $4 p^{4} G_{7 / 2}^{o}$ & $1.28 \mathrm{E}-01$ & 946 & 587 & \\
\hline & $4 s^{4} F_{9 / 2}$ & $4 p^{4} G_{9 / 2}^{o}$ & $1.15 \mathrm{E}-01$ & 947 & 936 & \\
\hline & $4 s^{4} F_{5 / 2}$ & $4 p^{4} G_{5 / 2}^{o}$ & $1.03 \mathrm{E}-01$ & 951 & 738 & \\
\hline & $4 s{ }^{4} F_{3 / 2}^{5 / 2}$ & $4 p^{4} G_{5 / 2}^{5 / 2}$ & $2.62 \mathrm{E}-01$ & 965 & 912 & \\
\hline & $4 s^{4} F_{5 / 2}^{3 / 2}$ & $4 p^{4} G_{7 / 2}^{0}$ & $1.96 \mathrm{E}-01$ & 968 & 721 & \\
\hline & $4 s^{4} F_{7 / 2}^{3 / 2}$ & $4 p^{4} G_{9 / 2}^{o}$ & $1.81 \mathrm{E}-01$ & 971 & 391 & \\
\hline & $4 s^{2} F_{7 / 2}$ & $4 p^{4} G_{9 / 2}^{o / 2}$ & $1.81 \mathrm{E}-01$ & 1039 & 890 & \\
\hline
\end{tabular}

Notes. The $f$ values of Ge IV are from Nath Dutta \& Majumder (2011). All Ge V and VI wavelengths are calculated from energy levels in Tables 1 and 3 unless otherwise mentioned in the comment column. 
increased $\mathrm{C}$ abundance would strengthen $\mathrm{C}$ IV lines as well, e.g. C IV $\lambda \lambda 948.09,948.21 \AA$ (Fig. 3), this is evidence that $T_{\text {eff }}$ of the model is too high and/or $\log g$ is too low. A respective variation would change the $\mathrm{C}$ III/ $\mathrm{C}$ IV ionization equilibrium towards the lower ionization and improve the agreement of the $\mathrm{C}$ III lines. Figures 4 and 5 demonstrate this for $T_{\text {eff }}=70 \mathrm{kK}$ and $T_{\text {eff }}=65 \mathrm{kK}$. We compared theoretical He I, He II, C III, C IV, $\mathrm{O} I \mathrm{~V}$, and $\mathrm{OV}$ line profiles with FUSE and GHRS UV observations and optical UVES observations. The most prominent C III $\lambda 977.020 \AA$ has a strong, blue-shifted interstellar component and is not well suited to an analysis. The better agreement of $\mathrm{C}_{\mathrm{III}} \lambda \lambda 1175 \AA$ in the line cores favors $T_{\mathrm{eff}}=65 \mathrm{kK}$, while the "shoulders" between the $C_{\text {III }} \lambda \lambda 1175 \AA$ components are better matched at $T_{\text {eff }}=70 \mathrm{kK}$. The lower $T_{\text {eff }}$ is supported by the $\mathrm{Ge} \mathrm{IV} / \mathrm{Ge} \mathrm{V}$ ionization balance (Fig. 6), if we judge e.g. Ge IV $\lambda 936.765 \AA$. The Ge v lines appear almost with same strengths in both $\left(T_{\text {eff }}=70 \mathrm{kK}\right.$ and $\left.T_{\text {eff }}=65 \mathrm{kK}\right)$ models. On the other hand, $\mathrm{Kr}$ vi $/ \mathrm{Kr}$ vII favors $T_{\text {eff }}=70 \mathrm{kK}$ (Werner et al. 2012), and $\mathrm{He}_{\mathrm{I}} \lambda 4471 \AA$ is too strong in the model at $T_{\text {eff }}=65 \mathrm{kK}$ (Fig. 6). The $\mathrm{O}$ IV $/ \mathrm{O} \mathrm{v}$ ionization appears unchanged between $T_{\text {eff }}=65 \mathrm{kK}$ and $T_{\text {eff }}=70 \mathrm{kK}$.

It is worthwhile mentioning that a lower $T_{\text {eff }}$ would strongly improve the agreement between model and the observed EUV flux (EUVE J0503-28.8, Werner et al. 2001). A more precise determination of $T_{\text {eff }}$ and $\log g$ of RE 0503-289 based on additional high-signal-to-noise ratio $(\mathrm{S} / \mathrm{N})$ optical spectra and more ionization equilibria of different species is highly desirable. Our test calculations have shown that our Ge line identifications and abundance determination are affected only marginally by this uncertainty in atmosphere parameters.

\section{Results and conclusions}

Successful reproduction of the identified Ge lines in highresolution UV spectra of RE 0503-289 by our synthetic spectra calculated from NLTE model atmospheres using newly calculated oscillator strengths of Gev and Ge vi shows that - when done with sufficient care - theory works.

We derive a photospheric abundance of $\log \mathrm{Ge}=-3.8 \pm 0.3$ (mass fraction) in RE 0503-289. This is about 650 times the solar abundance. This high value is similar to the results of Werner et al. (2012) for $\mathrm{Kr}$ (450 times solar) and $\mathrm{Xe}$ (3800 times solar).

The identifications of trans-iron elements in the FUSE spectrum of RE 0503-289 and the abundance determinations of Ge, $\mathrm{Kr}$, and Xe show that RE0503-289 is important for our understanding of the non-DA white dwarf evolutionary channel. Further abundance determinations of the identified species is highly desirable. This is a challenge for atomic physicists.

It is worthwhile mentioning here the two HST observations of RE 0503-289 taken with STIS ${ }^{16}$ (1999-03-23, ObsIds O56401010, O56401020) that missed the star because the prior target acquisition apparently failed. Unfortunately, they were not repeated. The available GHRS ${ }^{17}$ observations cover only small wavelength sections of the NUV, and the IUE high-resolution spectra (e.g. SWP52803HL) have too-low an S/N. Obtaining high-resolution, high S/N spectra with HST/STIS should not be missed because the NUV spectrum probably offers important, additional spectral information.

The Ge model ions that were used in this analysis were developed in the framework of the Virtual Observatory $\left(\mathrm{VO}^{18}\right)$ in a German Astrophysical Virtual Observatory $\left(\mathrm{GAVO}^{19}\right)$ project and are provided within TMAD (Sect.4). The spectral energy distribution of our final model can be retrieved in VO-compliant form via the registered VO service TheoSSA ${ }^{20}$.

Acknowledgements. T.R. is supported by the German Aerospace Center (DLR, grant 05 OR 0806). Financial support from the Belgian FRS-FNRS is also acknowledged. E.B. and P.Q. are Research Director and Senior Research Associate, respectively, of this organization. This research has made use of the SIMBAD database, operated at the CDS, Strasbourg, France. We thank Ralf Napiwotzki for providing us the SPY spectrum of RE 0503-289. Some of the data presented in this paper were obtained from the Mikulski Archive for Space Telescopes (MAST). STScI is operated by the Association of Universities for Research in Astronomy, Inc., under NASA contract NAS5-26555. Support for MAST for non-HST data is provided by the NASA Office of Space Science via grant NNX09AF08G and by other grants and contracts.

\section{References}

Biémont, E., \& Hansen, J. E. 1989, Phys. Scr., 39, 308

Churilov, S. S., Joshi, Y. N., Ryabtsev, A. N., \& Hanlon, M. 1997, Phys. Scr., 55,54

Cowan, R. D. 1981, The theory of atomic structure and spectra (Berkeley, CA: University of California Press)

Grant, I. P., \& McKenzie, B. J. 1980, J. Phys. B At. Mol. Phys., 13, 2671

Grant, I. P., McKenzie, B. J., Norrington, P. H., Mayers, D. F., \& Pyper, N. C. 1980, Comp. Phys. Comm., 21, 207

Hamasha, S. M., Shlyaptseva, A. S., \& Safronova, U. I. 2004, Can. J. Phys., 82, 331

Holberg, J. B., Barstow, M. A., \& Sion, E. M. 1998, ApJS, 119, 207

Jucys, A., Vizbaraite, J., \& Karazija, R. 1968, Liet. Fiz. Rinkinys, 8, 551

Napiwotzki, R., Christlieb, N., Drechsel, H., et al. 2001, Astron. Nachr., 322, 411

Napiwotzki, R., Christlieb, N., Drechsel, H., et al. 2003, The Messenger, 112, 25 Nath Dutta, N., \& Majumder, S. 2011, ApJ, 737, 25

Quinet, P., \& Biémont, E. 1990, Bull. Soc. R. Sci. Liège, 59, 307

Quinet, P., \& Biémont, E. 1991, Phys. Scr., 43, 150

Rauch, T., \& Deetjen, J. L. 2003, in Stellar Atmosphere Modeling, eds. I. Hubeny, D. Mihalas, \& K. Werner, ASP Conf. Ser., 288, 103

Safronova, U. I., \& Safronova, A. S. 2006, J. Plasma Fusion Res. Ser., 7, 278

Safronova, U. I., Johnson, W. R., \& Albritton, J. R. 2000, Phys. Rev. A, 62, 052505

Safronova, U. I., Safronova, A. S., \& Beiersdorfer, P. 2006a, J. Phys. B At. Mol. Phys. Opt., 39, 4491

Safronova, U. I., Safronova, A. S., Hamasha, S. M., \& Beiersdorfer, P. 2006b, Atomic Data and Nuclear Data Tables, 92, 47

Savitzky, A., \& Golay, M. J. E. 1964, Anal. Chem., 36, 1627

Seaton, M. J. 1962, in Atomic and Molecular Processes, ed. D. R. Bates, 375

Sugar, J., \& Musgrove, A. 1993, J. Phys. Chem. Ref. Data, 22, 1213

van Regemorter, H. 1962, ApJ, 136, 906

Werner, K., Deetjen, J. L., Rauch, T., \& Wolff, B. 2001, in 12th European Workshop on White Dwarfs, eds. J. L. Provencal, H. L. Shipman, J. MacDonald, \& S. Goodchild, ASP Conf. Ser., 226, 55

Werner, K., Deetjen, J. L., Dreizler, S., et al. 2003, in Stellar Atmosphere Modeling, eds. I. Hubeny, D. Mihalas, \& K. Werner, ASP Conf. Ser., 288, 31

Werner, K., Rauch, T., Ringat, E., \& Kruk, J. W. 2012, ApJ, 753, L7

Pages 7 to 13 are available in the electronic edition of the journal at http://wWw . aanda. org

\footnotetext{
16 Space Telescope Imaging Spectrograph.

${ }^{17}$ Goddard High Resolution Spectrograph.
}

\footnotetext{
$\overline{18 \text { http://www.ivoa.net/ }}$

19 http://www.g-vo.org

${ }^{20}$ http://dc.g-vo.org/theossa
} 


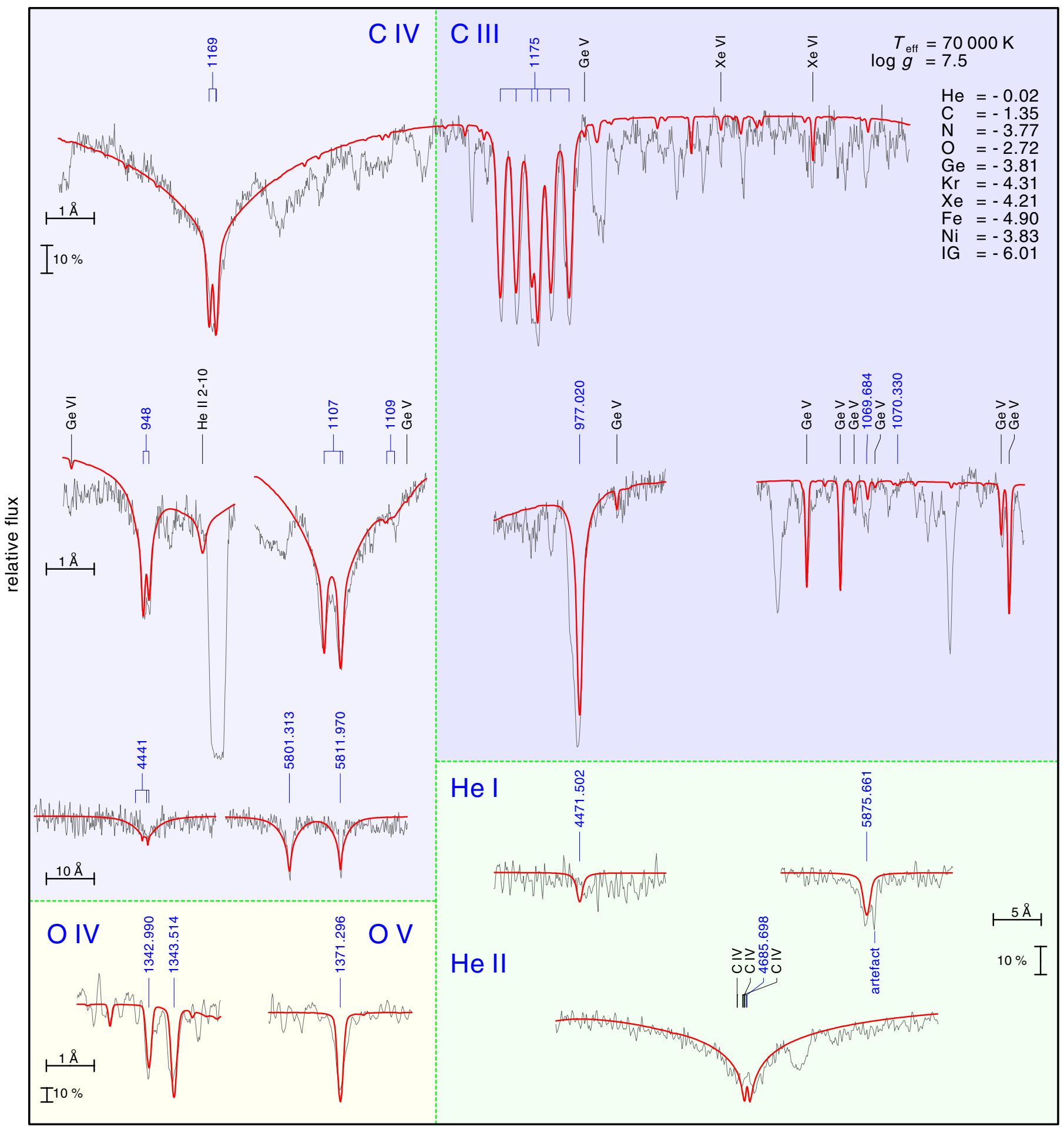

$\Delta \lambda / \AA$

Fig. 4. He I / He II, C III / C IV, and O IV / O v ionization equilibria in our $T_{\text {eff }}=70 \mathrm{kK}$ model compared with FUSE, GHRS (smoothed with a low-pass filter $(m=15, n=4)$ for clarity, Savitzky \& Golay 1964), and UVES observations. Wavelength and flux scales are indicated by bars. The model spectrum is convolved with a Gaussian to match the respective instrument's resolution. Unidentified lines in the model stem from Ca-Ni. 


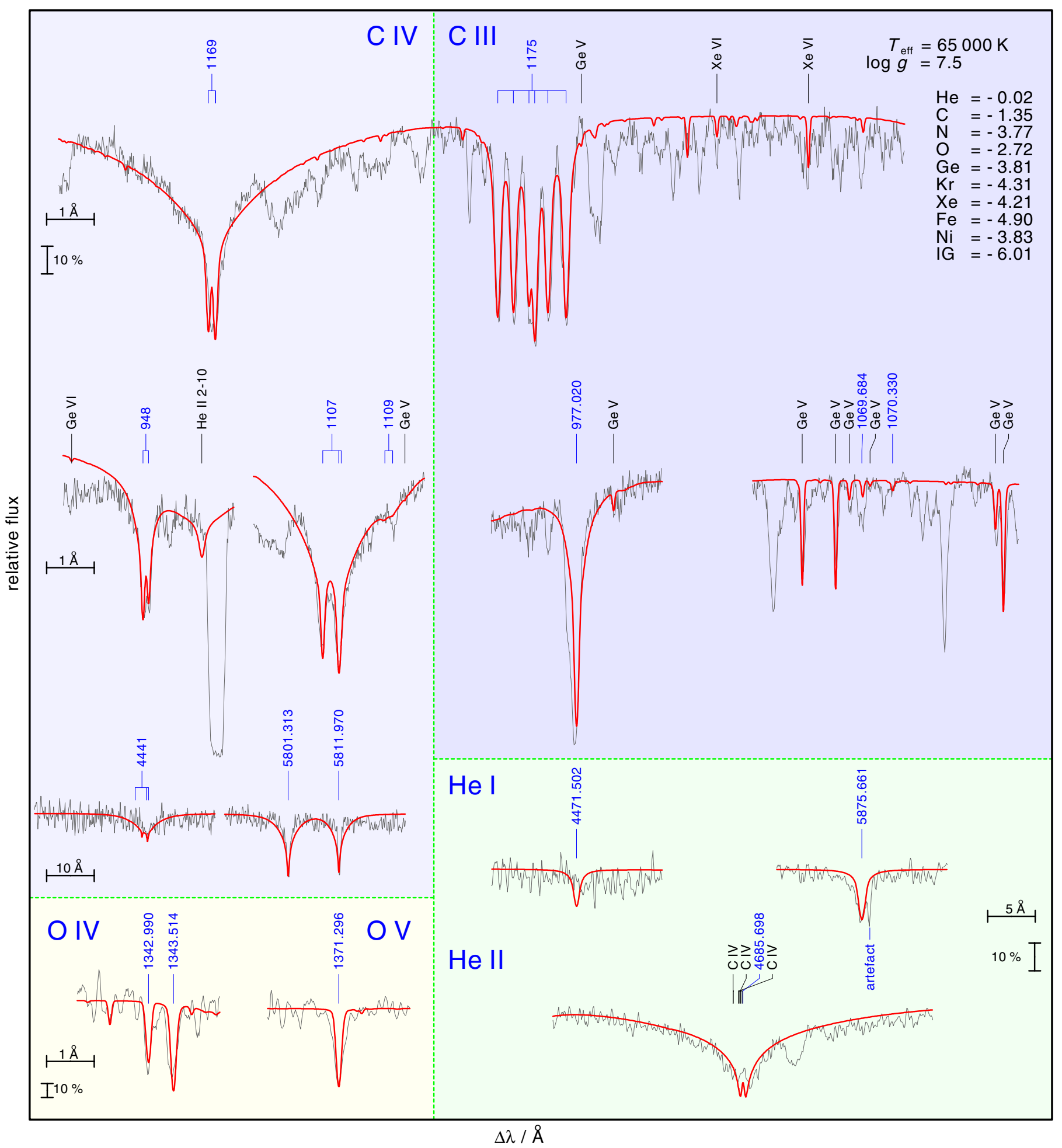

Fig. 5. Same as Fig. 4 for $T_{\text {eff }}=65 \mathrm{kK}$. 
T. Rauch et al.: Stellar laboratories: new Ge V and Ge VI oscillator strengths

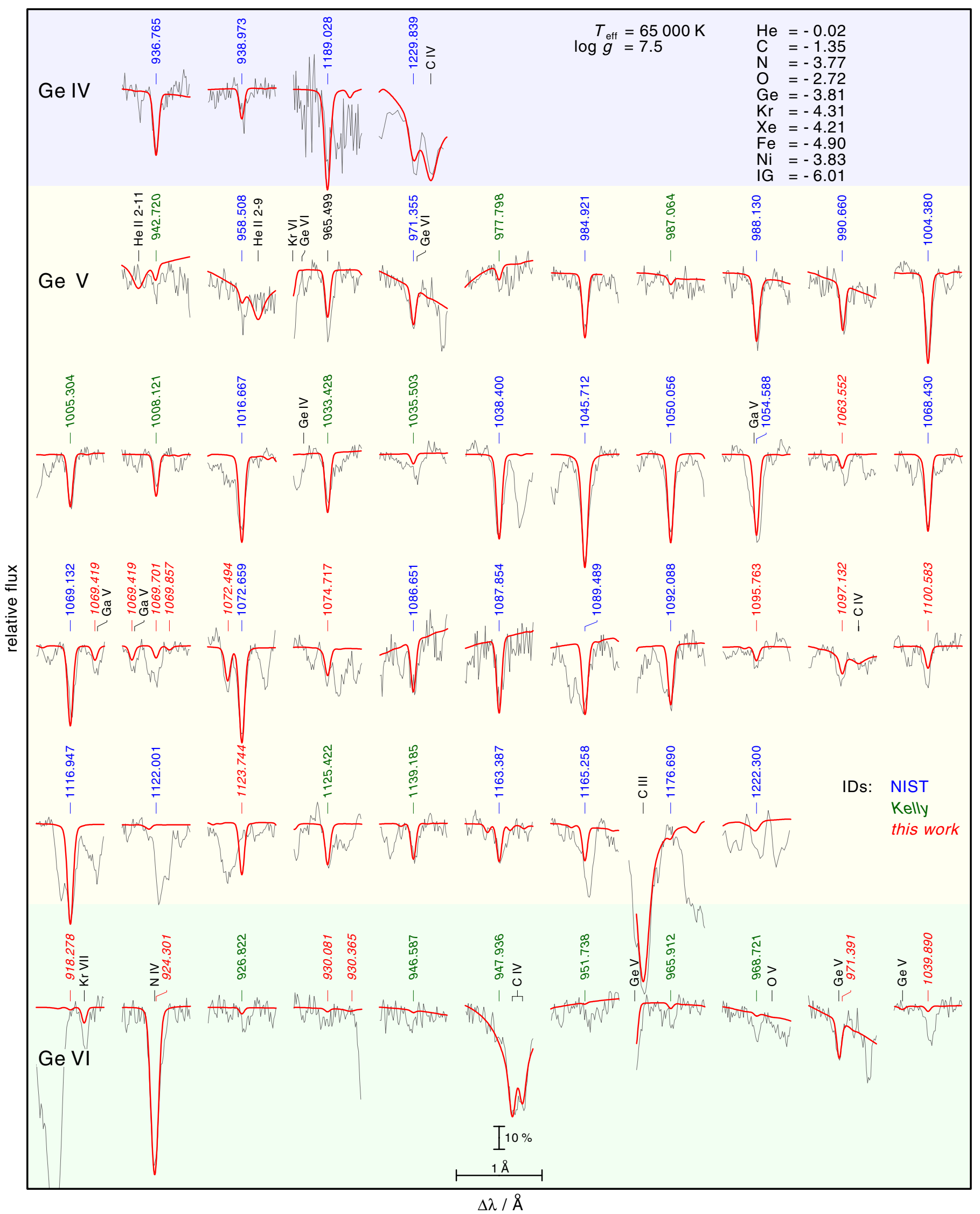

Fig. 6. Same as Fig. 3 for $T_{\text {eff }}=65 \mathrm{kK}$. 
A\&A 546, A55 (2012)

Table 1. Energy levels of Ge v (in $\mathrm{cm}^{-1}$ ). The first three LS-components are given when they are over 5\%.

\begin{tabular}{|c|c|c|c|c|}
\hline$E_{\text {exp }}$ & $E_{\text {calc }}$ & $\Delta E$ & $J$ & LS-coupling composition (\%) \\
\hline 0.0 & 0 & 0 & 0 & $993 d^{10}{ }^{1} S$ \\
\hline 234219.3 & 234226 & -7 & 3 & $993 d^{9} 4 s^{3} D$ \\
\hline 235967.0 & 235958 & 9 & 2 & $833 \mathrm{~d}^{9} 4 \mathrm{~s}^{3} \mathrm{D}$ \\
\hline 238764.9 & 238765 & -4 & 1 & $993 \mathrm{~d}^{9} 4 \mathrm{~s}^{3} \mathrm{D}$ \\
\hline 241935.2 & 241937 & -2 & 2 & $833 \mathrm{~d}^{9} 4 \mathrm{~s}^{1} \mathrm{D}$ \\
\hline 323748.9 & 323877 & -128 & 2 & $963 \mathrm{~d}^{9} 4 \mathrm{p}^{3} \mathrm{P}^{\circ}$ \\
\hline 327753.0 & 327889 & -136 & 1 & $963 \mathrm{~d}^{9} 4 \mathrm{p}^{3} \mathrm{P}^{\circ}$ \\
\hline 327891.0 & 327792 & 99 & 3 & $683 d^{9} 4 p^{3} F^{\circ}+273 d^{9} 4 p^{1} F^{\circ}$ \\
\hline 329847.8 & 329698 & 150 & 4 & $993 d^{9} 4 p^{3} F^{\circ}$ \\
\hline 330332.5 & 330250 & 83 & 0 & $993 d^{9} 4 p^{3} P^{\circ}$ \\
\hline 330790.6 & 330735 & 56 & 2 & $943 d^{9} 4 p^{3} F^{\circ}$ \\
\hline 335161.3 & 335214 & -52 & 3 & $603 d^{9} 4 p^{1} F^{\circ}+273 d^{9} 4 p^{3} D^{\circ}+123 d^{9} 4 p^{3} F^{\circ}$ \\
\hline 335560.3 & 335621 & -61 & 2 & $633 \mathrm{~d}^{9} 4 \mathrm{p}{ }^{1} \mathrm{D}^{\circ}+323 \mathrm{~d}^{9} 4 \mathrm{p}^{3} \mathrm{D}^{\circ}$ \\
\hline 337168.1 & 337131 & 37 & 3 & $683 d^{9} 4 p^{3} D^{\circ}+193 d^{9} 4 p^{3} F^{\circ}+133 d^{9} 4 p^{1} F^{\circ}$ \\
\hline 338273.5 & 338268 & 5 & 1 & $753 d^{9} 4 p^{1} P^{\circ}+243 d^{9} 4 p^{3} D^{\circ}$ \\
\hline 339540.2 & 339552 & -12 & 1 & $733 d^{9} 4 p^{3} D^{\circ}+233 d^{9} 4 p^{1} P^{\circ}$ \\
\hline 340295.7 & 340337 & -42 & 2 & $603 d^{9} 4 p^{3} D^{\circ}+363 d^{9} 4 p^{1} D^{\circ}$ \\
\hline 456051.8 & 456107 & -55 & 1 & $923 d^{9} 4 d^{3} S+63 d^{9} 4 d^{3} P$ \\
\hline 461417.5 & 461286 & 131 & 5 & $993 d^{9} 4 d^{3} G$ \\
\hline 461642.6 & 461607 & 36 & 4 & $643 d^{9} 4 d^{3} G+343 d^{9} 4 d^{1} G$ \\
\hline 461814.9 & 461908 & -93 & 1 & $503 d^{9} 4 d^{1} P+303 d^{9} 4 d^{3} P+193 d^{9} 4 d^{3} D$ \\
\hline 461828.5 & 461834 & -6 & 2 & $783 d^{9} 4 d^{3} P+213 d^{9} 4 d^{3} D$ \\
\hline 463361.6 & 463383 & -21 & 3 & $853 d^{9} 4 d^{3} D+113 d^{9} 4 d^{3} F$ \\
\hline 463957.9 & 463958 & 0 & 0 & $993 d^{9} 4 d^{3} P$ \\
\hline 464077.0 & 464020 & 57 & 3 & $633 d^{9} 4 d^{3} G+213 d^{9} 4 d^{1} F+113 d^{9} 4 d^{3} F$ \\
\hline 464652.2 & 464660 & -7 & 2 & $513 d^{9} 4 d^{3} D+233 d^{9} 4 d^{1} D+133 d^{9} 4 d^{3} P$ \\
\hline 464705.7 & 464754 & -49 & 4 & $523 d^{9} 4 d^{3} F+353 d^{9} 4 d^{1} G+123 d^{9} 4 d^{3} G$ \\
\hline 464852.7 & 464848 & 4 & 1 & $553 d^{9} 4 d^{3} P+373 d^{9} 4 d^{1} P+73 d^{9} 4 d^{3} S$ \\
\hline 466780.2 & 466778 & 2 & 3 & $383 d^{9} 4 d^{1} F+343 d^{9} 4 d^{3} G+273 d^{9} 4 d^{3} F$ \\
\hline 467029.1 & 466994 & 35 & 1 & $813 d^{9} 4 d^{3} D+113 d^{9} 4 d^{1} P+83 d^{9} 4 d^{3} P$ \\
\hline 467386.7 & 467371 & 16 & 4 & $463 d^{9} 4 d^{3} F+303 d^{9} 4 d^{1} G+233 d^{9} 4 d^{3} G$ \\
\hline 468695.8 & 468676 & 20 & 2 & $333 d^{9} 4 d^{1} D+313 d^{9} 4 d^{3} F+283 d^{9} 4 d^{3} D$ \\
\hline 469686.4 & 469746 & -59 & 3 & $503 d^{9} 4 d^{3} F+403 d^{9} 4 d^{1} F+93 d^{9} 4 d^{3} D$ \\
\hline 469889.6 & 469901 & -12 & 2 & $563 d^{9} 4 d^{3} F+433 d^{9} 4 d^{1} D$ \\
\hline 490741.7 & 490744 & -2 & 3 & $1003 d^{9} 5 s^{3} \mathrm{D}$ \\
\hline 491443.3 & 491441 & 2 & 2 & $553 d^{9} 5 s^{3} D+453 d^{9} 5{ }^{1} D$ \\
\hline 495288.4 & 495287 & 1 & 1 & $1003 d^{9} 5 s^{3} \mathrm{D}$ \\
\hline 495907.7 & 495909 & -2 & 2 & $553 d^{9} 5 s^{1} D+453 d^{9} 5 s^{3} D$ \\
\hline 522959.0 & 522993 & -34 & 2 & $933 d^{9} 5 p^{3} \mathrm{P}^{\circ}+73 \mathrm{~d}^{9} 5 \mathrm{p}^{3} \mathrm{D}^{\circ}$ \\
\hline 524232.0 & 524228 & 4 & 3 & $573 d^{9} 5 p^{3} F^{\circ}+363 d^{9} 5 p^{1} F^{\circ}+63 d^{9} 5 p^{3} D^{\circ}$ \\
\hline 524950.0 & 524897 & 53 & 4 & $1003 d^{9} 5 p^{3} F^{\circ}$ \\
\hline 525343.0 & 525357 & -14 & 1 & $723 d^{9} 5 p^{3} \mathrm{P}^{\circ}+223 d^{9} 5 p^{1} \mathrm{P}^{\circ}+63 d^{9} 5 p^{3} \mathrm{D}^{\circ}$ \\
\hline 526373.0 & 526383 & -10 & 2 & $413 d^{9} 5 p^{1} D^{\circ}+303 d^{9} 5 p^{3} D^{\circ}+263 d^{9} 5 p^{3} F^{\circ}$ \\
\hline 526902.0 & 526908 & -6 & 3 & $803 d^{9} 5 p^{3} D^{\circ}+193 d^{9} 5 p{ }^{1} F^{\circ}$ \\
\hline 528156.0 & 528159 & -3 & 0 & $1003 d^{9} 5 p^{3} \mathrm{P}^{\circ}$ \\
\hline 528625.0 & 528600 & 25 & 2 & $713 d^{9} 5 p^{3} F^{\circ}+263 d^{9} 5 p^{1} D^{\circ}$ \\
\hline 529476.0 & 529472 & 4 & 1 & $773 d^{9} 5 p^{1} P^{\circ}+223 d^{9} 5 p^{3} P$ \\
\hline 530113.0 & 530114 & -1 & 3 & $443 d^{9} 5 p^{1} F^{\circ}+423 d^{9} 5 p^{3} F^{\circ}+143 d^{9} 5 p^{3} D^{\circ}$ \\
\hline 530928.0 & 530919 & 9 & 1 & $943 d^{9} 5 p^{3} D^{\circ}$ \\
\hline 531321.0 & 531348 & -27 & 2 & $603 d^{9} 5 p^{3} D^{\circ}+333 d^{9} 5 p^{1} D^{\circ}$ \\
\hline 553910.9 & 553895 & 16 & 1 & $883 \mathrm{~d}^{9} 4 \mathrm{f}^{3} \mathrm{P}^{\circ}+103 \mathrm{~d}^{9} 4 \mathrm{f}^{3} \mathrm{D}^{\circ}$ \\
\hline 554370.9 & 554374 & -3 & 2 & $563 \mathrm{~d}^{9} 4 \mathrm{f}^{3} \mathrm{P}^{\circ}+273 \mathrm{~d}^{9} 4 \mathrm{f}^{3} \mathrm{D}^{\circ}+173 \mathrm{~d}^{9} 4 \mathrm{f}^{1} \mathrm{D}^{\circ}$ \\
\hline 554658.0 & 554671 & -13 & 6 & $1003 d^{9} 4 f^{3} \mathrm{H}^{\circ}$ \\
\hline 554690.2 & 554714 & -24 & 5 & $533 d^{9} 4 f^{1} H^{\circ}+473 d^{9} 4 f^{3} H^{\circ}$ \\
\hline 555298.8 & 555305 & -6 & 2 & $403 d^{9} 4 f^{1} D^{\circ}+333 d^{9} 4 f^{3} F^{\circ}+263 d^{9} 4 f^{3} D^{\circ}$ \\
\hline 555337.1 & 555318 & 19 & 3 & $663 d^{9} 4 f^{3} D^{\circ}+253 d^{9} 4 f^{3} F+83 d^{9} 4 f^{1} F$ \\
\hline 555730.2 & 555717 & 13 & 1 & $593 \mathrm{~d}^{9} 4 \mathrm{f}^{3} \mathrm{D}^{\circ}+373 \mathrm{~d}^{9} 4 \mathrm{f}^{1} \mathrm{P}^{\circ}$ \\
\hline 555798.4 & 555792 & 6 & 4 & $763 d^{9} 4 f^{3} F^{\circ}+203 d^{9} 4 f^{3} G^{\circ}$ \\
\hline 555852.3 & 555858 & -6 & 5 & $793 d^{9} 4 f^{3} G^{\circ}+113 d^{9} 4 f^{3} H^{\circ}+113 d^{9} 4 f^{1} H^{\circ}$ \\
\hline 555860.0 & 555862 & -2 & 4 & $493 d^{9} 4 f^{1} G^{\circ}+283 d^{9} 4 f^{3} G^{\circ}+213 d^{9} 4 f^{3} H^{\circ}$ \\
\hline 555912.7 & 555912 & 1 & 3 & $473 \mathrm{~d}^{9} 4 \mathrm{f}^{1} \mathrm{~F}^{\circ}+283 \mathrm{~d}^{9} 4 \mathrm{f}^{3} \mathrm{~F}^{\circ}+233 \mathrm{~d}^{9} 4 \mathrm{f}^{3} \mathrm{G}^{\circ}$ \\
\hline 558877.1 & 558871 & 6 & 2 & $443 d^{9} 4 f^{3} \mathrm{P}^{\circ}+343 \mathrm{~d}^{9} 4 \mathrm{f}^{3} \mathrm{D}^{\circ}+223 \mathrm{~d}^{9} 4 \mathrm{f}^{1} \mathrm{D}^{\circ}$ \\
\hline 559463.1 & 559452 & 11 & 4 & $783 d^{9} 4 f^{3} H^{\circ}+123 d^{9} 4 f^{1} G^{\circ}+103 d^{9} 4 f^{3} G^{\circ}$ \\
\hline 559467.6 & 559487 & -20 & 5 & $423 d^{9} 4 f^{3} H^{\circ}+373 d^{9} 4 f^{1} H^{\circ}+213 d^{9} 4 f^{3} G^{\circ}$ \\
\hline
\end{tabular}


T. Rauch et al.: Stellar laboratories: new Ge V and Ge VI oscillator strengths

Table 1. continued.

\begin{tabular}{|c|c|c|c|c|}
\hline$E_{\exp }$ & $E_{\text {calc }}$ & $\Delta E$ & $J$ & LS-coupling composition (\%) \\
\hline 560034.6 & 560024 & 11 & 2 & $663 d^{9} 4 f^{3} F^{\circ}+213 d^{9} 4 f^{1} D^{\circ}+133 d^{9} 4 f^{3} D^{\circ}$ \\
\hline 560096.6 & 560095 & 2 & 3 & $413 d^{9} 4 f^{3} F^{\circ}+323 d^{9} 4 f^{3} D^{\circ}+263 d^{9} 4 f^{1} F^{\circ}$ \\
\hline 560149.3 & 560157 & -7 & 1 & $603 d^{9} 4 f^{1} P^{\circ}+303 d^{9} 4 f^{3} D^{\circ}+93 d^{9} 4 f^{3} P^{\circ}$ \\
\hline 560547.2 & 560559 & -12 & 4 & $433 d^{9} 4 f^{3} G^{\circ}+353 d^{9} 4 f^{1} G^{\circ}+223 d^{9} 4 f^{3} F^{\circ}$ \\
\hline 560587.7 & 560579 & 9 & 3 & $763 d^{9} 4 f^{3} G^{\circ}+183 d^{9} 4 f^{1} F^{\circ}+63 d^{9} 4 f^{3} F^{\circ}$ \\
\hline 574389.0 & 574404 & -14 & 1 & $793 d^{9} 5 d^{3} S+153 d^{9} 5 d^{3} P$ \\
\hline 576067.0 & 576047 & 20 & 5 & $1003 d^{9} 5 d^{3} G$ \\
\hline 576226.0 & 576206 & 20 & 4 & $553 d^{9} 5 d^{3} G+443 d^{9} 5 d^{1} G$ \\
\hline 576963.0 & 576934 & 29 & 3 & $843 d^{9} 5 d^{3} D+133 d^{9} 5 d^{3} F$ \\
\hline 577459.0 & 577444 & 15 & 3 & $483 d^{9} 5 d^{1} F+293 d^{9} 5 d^{3} F+223 d^{9} 5 d^{3} G$ \\
\hline 577553.0 & 577623 & -79 & 4 & $803 d^{9} 5 d^{3} F+143 d^{9} 5 d^{1} G$ \\
\hline 580695.0 & 580724 & -29 & 3 & $783 d^{9} 5 d^{3} G+143 d^{9} 5 d^{1} F+83 d^{9} 5 d^{3} F$ \\
\hline 581114.0 & 581106 & 8 & 4 & $413 d^{9} 5 d^{1} G+403 d^{9} 5 d^{3} G+193 d^{9} 5 d^{3} F$ \\
\hline 582225.0 & 582201 & 24 & 3 & $503 d^{9} 5 d^{3} F+363 d^{9} 5 d^{1} F+143 d^{9} 5 d^{3} D$ \\
\hline 582308.0 & 582311 & -3 & 2 & $683 d^{9} 5 d^{3} F+303 d^{9} 5 d^{1} D$ \\
\hline 588094.0 & 588095 & -1 & 3 & $1003 d^{9} 6 s^{3} \mathrm{D}$ \\
\hline 588403.0 & 588402 & 1 & 2 & $543 d^{9} 6 s{ }^{1} D+463 d^{9} 6 s^{3} D$ \\
\hline 592644.0 & 592643 & 1 & 1 & $1003 d^{9} 6 s^{3} \mathrm{D}$ \\
\hline 592872.0 & 592873 & -1 & 2 & $543 d^{9} 6{ }^{3} D+463 d^{9} 6 s^{1} D$ \\
\hline 601967.0 & 602124 & -157 & 4 & $763 d^{8} 4 s\left({ }^{4} F\right) 4 p^{5} F^{\circ}+93 d^{8} 4 s\left({ }^{4} F\right) 4 p^{5} G^{\circ}$ \\
\hline 603355.0 & 603363 & -8 & 2 & $903 d^{9} 6 p^{3} \mathrm{P}^{\circ}+93 \mathrm{~d}^{9} 6 \mathrm{p}^{3} \mathrm{D}^{\circ}$ \\
\hline 603929.0 & 603934 & -5 & 3 & $523 d^{9} 6 p^{3} F^{\circ}+403 d^{9} 6 p^{1} F^{\circ}+73 d^{9} 6 p^{3} D^{\circ}$ \\
\hline 604182.0 & 604165 & 17 & 4 & $873 \mathrm{~d}^{9} 6 \mathrm{p}^{3} \mathrm{~F}^{\circ}$ \\
\hline 604278.0 & 604253 & 25 & 4 & $313 d^{8} 4 s\left({ }^{2} F\right) 4 p^{3} G^{\circ}+233 d^{8} 4 s\left({ }^{2} F\right) 4 p{ }^{1} G^{\circ}+153 d^{8} 4 s\left({ }^{4} F\right) 4 p^{3} G^{\circ}$ \\
\hline 604648.0 & 604656 & -8 & 1 & $483 \mathrm{~d}^{9} 6 \mathrm{p}^{3} \mathrm{P}^{\circ}+413 \mathrm{~d}^{9} 6 \mathrm{p}^{1} \mathrm{P}^{\circ}+83 \mathrm{~d}^{9} 6 \mathrm{p}^{3} \mathrm{D}^{\circ}$ \\
\hline 604928.0 & 604922 & 6 & 3 & $423 d^{9} 6 p^{3} D^{\circ}+263 d^{8} 4 s\left({ }^{2} F\right) 4 p^{3} D^{\circ}+113 d^{8} 4 s\left({ }^{4} F\right) 4 p^{3} D^{\circ}$ \\
\hline 604935.0 & 604910 & 25 & 2 & $543 \mathrm{~d}^{9} 6 \mathrm{p}^{1} \mathrm{D}^{\circ}+313 \mathrm{~d}^{9} 6 \mathrm{p}^{3} \mathrm{D}^{\circ}+103 \mathrm{~d}^{9} 6 \mathrm{p}^{3} \mathrm{~F}^{\circ}$ \\
\hline 605218.0 & 605263 & -45 & 3 & $423 d^{9} 6 p^{3} D^{\circ}+263 d^{8} 4 s\left({ }^{2} F\right) 4 p^{3} D^{\circ}+83 d^{9} 6 p^{1} F^{\circ}$ \\
\hline 606815.0 & 606769 & 46 & 2 & $473 d^{8} 4 s\left({ }^{2} F\right) 4 p^{3} D^{\circ}+193 d^{8} 4 s\left({ }^{4} F\right) 4 p^{3} D^{\circ}+103 d^{8} 4 s\left({ }^{2} F\right) 4 p^{3} \mathrm{~F}^{\circ}$ \\
\hline 607097.0 & 607108 & -11 & 3 & $563 d^{8} 4 s\left({ }^{2} F\right) 4 p^{3} G^{\circ}+273 d^{8} 4 s\left({ }^{4} F\right) 4 p^{3} G^{\circ}+63 d^{8} 4 s\left({ }^{2} F\right) 4 p^{3} D^{\circ}$ \\
\hline 608207.0 & 608191 & 16 & 0 & $1003 \mathrm{~d}^{9} 6 \mathrm{p}^{3} \mathrm{P}^{\circ}$ \\
\hline 608340.0 & 608349 & -9 & 2 & $853 d^{9} 6 p^{3} F^{\circ}+143 d^{9} 6 p{ }^{1} D^{\circ}$ \\
\hline 608587.0 & 608664 & -77 & 1 & $543 \mathrm{~d}^{9} 6 \mathrm{p}^{1} \mathrm{P}^{\circ}+463 \mathrm{~d}^{9} 6 \mathrm{p}^{3} \mathrm{P}^{\circ}$ \\
\hline 609075.0 & 609063 & 12 & 3 & $473 d^{9} 6 p^{3} F^{\circ}+433 d^{9} 6 p^{1} F^{\circ}+93 d^{9} 6 p^{3} D^{\circ}$ \\
\hline 609083.0 & 608951 & 132 & 1 & $423 d^{8} 4 s\left({ }^{2} F\right) 4 p^{3} D^{\circ}+203 d^{8} 4 s\left({ }^{4} F\right) 4 p^{3} D^{\circ}+163 d^{9} 6 p^{3} D^{\circ}$ \\
\hline 609246.0 & 609294 & -48 & 4 & $533 \mathrm{~d}^{8} 4 \mathrm{~s}\left({ }^{2} \mathrm{~F}\right) 4 \mathrm{p}{ }^{3} \mathrm{~F}^{\circ}+323 \mathrm{~d}^{8} 4 \mathrm{~s}\left({ }^{4} \mathrm{~F}\right) 4 \mathrm{p}^{3} \mathrm{~F}^{\circ}+73 \mathrm{~d}^{8} 4 \mathrm{~s}\left({ }^{4} \mathrm{~F}\right) 4 \mathrm{p}^{5} \mathrm{~F}^{\circ}$ \\
\hline 609501.0 & 609531 & -30 & 1 & $763 d^{9} 6 p^{3} D^{\circ}+103 d^{8} 4 s\left({ }^{2} F\right) 4 p^{3} D^{\circ}$ \\
\hline 609609.0 & 609601 & 8 & 2 & $593 d^{9} 6 p^{3} D^{\circ}+313 d^{9} 6 p^{1} D^{\circ}+63 d^{9} 6 p^{3} P^{\circ}$ \\
\hline 609963.0 & 609943 & 20 & 3 & $323 d^{8} 4 s\left({ }^{2} F\right) 4 p^{3} F^{\circ}+233 d^{8} 4 s\left({ }^{2} F\right) 4 p{ }^{1} F^{\circ}+193 d^{8} 4 s\left({ }^{4} F\right) 4 p{ }^{3} F^{\circ}$ \\
\hline 611844.0 & 611865 & -21 & 2 & $493 d^{8} 4 s\left({ }^{2} F\right) 4 p^{3} F^{\circ}+273 d^{8} 4 s\left({ }^{4} F\right) 4 p^{3} F^{\circ}+83 d^{8} 4 s\left({ }^{2} F\right) 4 p{ }^{3} D^{\circ}$ \\
\hline 614161.0 & 614129 & 32 & 2 & $663 d^{8} 4 s\left({ }^{2} F\right) 4 p{ }^{1} D^{\circ}+143 d^{8} 4 s\left({ }^{4} P\right) 4 p{ }^{5} P^{\circ}+63 d^{8} 4 s\left({ }^{2} D\right) 4 p{ }^{3} \mathrm{P}^{\circ}$ \\
\hline 614754.0 & 614750 & 4 & 3 & $513 \mathrm{~d}^{8} 4 \mathrm{~s}\left({ }^{2} \mathrm{~F}\right) 4 \mathrm{p}^{1} \mathrm{~F}^{\circ}+163 \mathrm{~d}^{8} 4 \mathrm{~s}\left({ }^{4} \mathrm{P}\right) 4 \mathrm{p}^{5} \mathrm{P}^{\circ}+113 \mathrm{~d}^{8} 4 \mathrm{~s}\left({ }^{2} \mathrm{D}\right) 4 \mathrm{p}^{3} \mathrm{D}^{\circ}$ \\
\hline 615820.0 & 615814 & 6 & 2 & $703 d^{8} 4 s\left({ }^{4} \mathrm{P}\right) 4 \mathrm{p}^{5} \mathrm{P}^{\circ}+183 \mathrm{~d}^{8} 4 \mathrm{~s}\left({ }^{2} \mathrm{~F}\right) 4 \mathrm{p}^{1} \mathrm{D}^{\circ}$ \\
\hline 617340.0 & 617318 & 22 & 1 & $813 \mathrm{~d}^{9} 5 \mathrm{f}^{3} \mathrm{P}^{\circ}+163 \mathrm{~d}^{9} 5 \mathrm{f}^{3} \mathrm{D}^{\circ}$ \\
\hline 618540.0 & 618619 & -79 & 1 & $543 d^{9} 5 f^{3} D^{\circ}+393 d^{9} 5 f^{1} P^{\circ}+73 d^{9} 5 f^{3} P^{\circ}$ \\
\hline 620940.0 & 620955 & -15 & 2 & $753 \mathrm{~d}^{8} 4 \mathrm{~s}\left({ }^{2} \mathrm{D}\right) 4 \mathrm{p}^{3} \mathrm{~F}^{\circ}$ \\
\hline 621888.0 & 621765 & 123 & 3 & $673 d^{8} 4 s\left({ }^{2} D\right) 4 p{ }^{3} F^{\circ}+73 d^{8} 4 s\left({ }^{4} P\right) 4 p{ }^{5} D^{\circ}+63 d^{8} 4 s\left({ }^{2} G\right) 4 p^{3} F^{\circ}$ \\
\hline 622200.0 & 622265 & -65 & 1 & $443 d^{8} 4 s\left({ }^{2} \mathrm{D}\right) 4 \mathrm{p}^{3} \mathrm{D}^{\circ}+163 \mathrm{~d}^{8} 4 \mathrm{~s}\left({ }^{2} \mathrm{D}\right) 4 \mathrm{p}^{3} \mathrm{P}^{\circ}+113 \mathrm{~d}^{8} 4 \mathrm{~s}\left({ }^{2} \mathrm{~F}\right) 4 \mathrm{p}^{3} \mathrm{D}^{\circ}$ \\
\hline 622627.0 & 622572 & 55 & 2 & $583 d^{9} 5 f^{3} F^{\circ}+193 d^{9} 5 f^{1} D^{\circ}+143 d^{9} 5 f^{3} D^{\circ}$ \\
\hline 622759.0 & 622566 & 193 & 4 & $343 d^{8} 4 s\left({ }^{2} D\right) 4 p{ }^{3} F^{\circ}+203 d^{9} 5 f^{3} G^{\circ}+183 d^{9} 5 f^{1} G^{\circ}$ \\
\hline 622980.0 & 623065 & -85 & 1 & $593 \mathrm{~d}^{9} 5 \mathrm{f}^{1} \mathrm{P}^{\circ}+283 \mathrm{~d}^{9} 5 \mathrm{f}^{3} \mathrm{D}^{\circ}+113 \mathrm{~d}^{9} 5 \mathrm{f}^{3} \mathrm{P}^{\circ}$ \\
\hline 623081.0 & 623121 & -40 & 2 & $523 d^{8} 4 s\left({ }^{2} D\right) 4 p{ }^{3} D^{\circ}+73 d^{8} 4 s\left({ }^{2} F\right) 4 p{ }^{3} D^{\circ}+73 d^{8} 4 s\left({ }^{2} D\right) 4 p{ }^{3} F^{\circ}$ \\
\hline 624057.0 & 624159 & -102 & 3 & $703 d^{8} 4 s\left({ }^{2} \mathrm{D}\right) 4 \mathrm{p}^{3} \mathrm{D}^{\circ}+83 \mathrm{~d}^{8} 4 \mathrm{~s}\left({ }^{4} \mathrm{P}\right) 4 \mathrm{p}^{5} \mathrm{P}^{\circ}$ \\
\hline 624684.0 & 624678 & 6 & 1 & $413 d^{8} 4 s\left({ }^{2} \mathrm{D}\right) 4 \mathrm{p}^{3} \mathrm{P}^{\circ}+323 \mathrm{~d}^{8} 4 \mathrm{~s}\left({ }^{2} \mathrm{D}\right) 4 \mathrm{p}^{3} \mathrm{D}^{\circ}+113 \mathrm{~d}^{8} 4 \mathrm{~s}\left({ }^{2} \mathrm{P}\right) 4 \mathrm{p}^{3} \mathrm{P}^{\circ}$ \\
\hline 625990.0 & 625902 & 88 & 2 & $673 d^{8} 4 s\left({ }^{2} D\right) 4 p^{3} P^{\circ}+153 d^{8} 4 s\left({ }^{2} D\right) 4 p{ }^{3} D^{\circ}$ \\
\hline 626651.0 & 626697 & -46 & 1 & $863 d^{8} 4 s\left({ }^{4} P\right) 4 p^{5} D^{\circ}+93 d^{8} 4 s\left({ }^{4} F\right) 4 p^{5} D^{\circ}$ \\
\hline 627067.0 & 626899 & 168 & 2 & $823 \mathrm{~d}^{8} 4 \mathrm{~s}\left({ }^{4} \mathrm{P}\right) 4 \mathrm{p}^{5} \mathrm{D}^{\circ}+73 \mathrm{~d}^{8} 4 \mathrm{~s}\left({ }^{4} \mathrm{~F}\right) 4 \mathrm{p}^{5} \mathrm{D}^{\circ}$ \\
\hline 627229.0 & 627336 & -107 & 3 & $763 d^{8} 4 s\left({ }^{4} P\right) 4 p{ }^{5} D^{\circ}+83 d^{8} 4 s\left({ }^{2} D\right) 4 p^{3} F^{\circ}+63 d^{8} 4 s\left({ }^{4} F\right) 4 p^{5} D^{\circ}$ \\
\hline 627958.0 & 627879 & 79 & 4 & $673 d^{8} 4 s\left({ }^{4} P\right) 4 p^{5} D^{\circ}+173 d^{8} 4 s\left({ }^{2} G\right) 4 p^{3} F^{\circ}+113 d^{8} 4 s\left({ }^{2} D\right) 4 p^{3} F^{\circ}$ \\
\hline 630288.0 & 630242 & 46 & 2 & $493 d^{8} 4 s\left({ }^{2} P\right) 4 p{ }^{3} P^{\circ}+163 d^{8} 4 s\left({ }^{4} P\right) 4 p^{3} P^{\circ}+133 d^{8} 4 s\left({ }^{2} P\right) 4 p^{3} D^{\circ}$ \\
\hline 631618.0 & 631645 & -27 & 1 & $343 d^{8} 4 s\left({ }^{2} \mathrm{P}\right) 4 \mathrm{p}^{3} \mathrm{P}^{\circ}+233 \mathrm{~d}^{8} 4 \mathrm{~s}\left({ }^{2} \mathrm{D}\right) 4 \mathrm{p}^{3} \mathrm{P}^{\circ}+173 \mathrm{~d}^{8} 4 \mathrm{~s}\left({ }^{2} \mathrm{P}\right) 4 \mathrm{p}^{3} \mathrm{D}^{\circ}$ \\
\hline 633144.0 & 633168 & -24 & 2 & $313 \mathrm{~d}^{8} 4 \mathrm{~s}\left({ }^{2} \mathrm{P}\right) 4 \mathrm{p}^{3} \mathrm{D}^{\circ}+163 \mathrm{~d}^{8} 4 \mathrm{~s}\left({ }^{4} \mathrm{P}\right) 4 \mathrm{p}^{3} \mathrm{D}^{\circ}+123 \mathrm{~d}^{8} 4 \mathrm{~s}\left({ }^{2} \mathrm{P}\right) 4 \mathrm{p}^{3} \mathrm{P}^{\circ}$ \\
\hline 633171.0 & 633282 & -111 & 1 & $413 \mathrm{~d}^{8} 4 \mathrm{~s}\left({ }^{2} \mathrm{P}\right) 4 \mathrm{p}^{3} \mathrm{D}^{\circ}+193 \mathrm{~d}^{8} 4 \mathrm{~s}\left({ }^{4} \mathrm{P}\right) 4 \mathrm{p}^{3} \mathrm{D}^{\circ}+143 \mathrm{~d}^{8} 4 \mathrm{~s}\left({ }^{2} \mathrm{P}\right) 4 \mathrm{p}^{1} \mathrm{P}^{\circ}$ \\
\hline 633258.0 & 633307 & -49 & 3 & $363 d^{8} 4 s\left({ }^{2} P\right) 4 p^{3} D^{\circ}+213 d^{8} 4 s\left({ }^{2} G\right) 4 p^{3} F^{\circ}+203 d^{8} 4 s\left({ }^{2} P\right) 4 p^{3} D^{\circ}$ \\
\hline
\end{tabular}


Table 1. continued.

\begin{tabular}{|c|c|c|c|c|}
\hline$E_{\text {exp }}$ & $E_{\text {calc }}$ & $\Delta E$ & $J$ & LS-coupling composition (\%) \\
\hline 633570.0 & 633575 & -5 & 0 & $453 \mathrm{~d}^{8} 4 \mathrm{~s}\left({ }^{2} \mathrm{P}\right) 4 \mathrm{p}^{3} \mathrm{P}^{\circ}+403 \mathrm{~d}^{8} 4 \mathrm{~s}\left({ }^{2} \mathrm{D}\right) 4 \mathrm{p}^{3} \mathrm{P}^{\circ}+103 \mathrm{~d}^{8} 4 \mathrm{~s}\left({ }^{4} \mathrm{P}\right) 4 \mathrm{p}^{3} \mathrm{P}^{\circ}$ \\
\hline 634154.0 & 634294 & -140 & 4 & $543 d^{8} 4 s\left({ }^{2} G\right) 4 p{ }^{3} F^{\circ}+213 d^{8} 4 s\left({ }^{2} D\right) 4 p{ }^{3} F^{\circ}+113 d^{8} 4 s\left({ }^{2} F\right) 4 p{ }^{3} F^{\circ}$ \\
\hline 635602.0 & 635662 & -60 & 3 & $513 d^{8} 4 s\left({ }^{2} G\right) 4 p^{3} F^{\circ}+143 d^{8} 4 s\left({ }^{2} D\right) 4 p^{3} F^{\circ}+133 d^{8} 4 s\left({ }^{2} P\right) 4 p^{3} D^{\circ}$ \\
\hline 635973.0 & 635974 & -1 & 3 & $1003 \mathrm{~d}^{9} 7 \mathrm{~s}^{3} \mathrm{D}$ \\
\hline 636143.0 & 636142 & 1 & 2 & $573 d^{9} 7 s^{1} D+433 d^{9} 7 s^{3} D$ \\
\hline 636503.0 & 636291 & 212 & 2 & $703 d^{8} 4 s\left({ }^{2} G\right) 4 p^{3} F^{\circ}+83 d^{8} 4 s\left({ }^{2} D\right) 4 p{ }^{3} F^{\circ}+73 d^{8} 4 s\left({ }^{2} F\right) 4 p^{3} F^{\circ}$ \\
\hline 637786.0 & 637827 & -41 & 3 & $563 \mathrm{~d}^{8} 4 \mathrm{~s}\left({ }^{4} \mathrm{~F}\right) 4 \mathrm{p}^{3} \mathrm{D}^{\circ}+193 \mathrm{~d}^{8} 4 \mathrm{~s}\left({ }^{2} \mathrm{~F}\right) 4 \mathrm{p}^{3} \mathrm{D}^{\circ}+103 \mathrm{~d}^{8} 4 \mathrm{~s}\left({ }^{4} \mathrm{P}\right) 4 \mathrm{p}^{3} \mathrm{D}^{\circ}$ \\
\hline 638636.0 & 638740 & -104 & 4 & $383 d^{8} 4 s\left({ }^{4} F\right) 4 p^{3} G^{\circ}+233 d^{8} 4 s\left({ }^{2} F\right) 4 p^{3} G^{\circ}+183 d^{8} 4 s\left({ }^{4} F\right) 4 p^{3} F^{\circ}$ \\
\hline 640509.0 & 640508 & 1 & 1 & $1003 \mathrm{~d}^{9} 7 \mathrm{~s}^{3} \mathrm{D}$ \\
\hline 640625.0 & 640626 & -1 & 2 & $573 d^{9} 7 s^{3} D+433 d^{9} 7 s^{1} D$ \\
\hline 640855.0 & 640666 & 189 & 4 & $363 d^{8} 4 s\left({ }^{4} F\right) 4 p^{3} F^{\circ}+203 d^{8} 4 s\left({ }^{4} F\right) 4 p^{3} G^{\circ}+193 d^{8} 4 s\left({ }^{2} F\right) 4 p^{3} F^{\circ}$ \\
\hline 641390.0 & 6413 & -2 & 2 & $563 d^{8} 4 s\left({ }^{4} F\right) 4 p^{3} D^{\circ}+223 d^{8} 4 s\left({ }^{2} F\right) 4 p^{3} D^{\circ}+83 d^{8} 4 s\left({ }^{4} P\right) 4 p^{3} D^{\circ}$ \\
\hline 643477.0 & 643461 & 16 & 1 & $563 d^{8} 4 s\left({ }^{4} F\right) 4 p^{3} D^{\circ}+243 d^{8} 4 s\left({ }^{2} F\right) 4 p^{3} D^{\circ}+73 d^{8} 4 s\left({ }^{4} P\right) 4 p{ }^{3} D^{\circ}$ \\
\hline 643724.0 & 643609 & 115 & 3 & $453 d^{8} 4 s\left({ }^{4} F\right) 4 p^{3} F^{\circ}+233 d^{8} 4 s\left({ }^{2} F\right) 4 p^{3} F^{\circ}+63 d^{8} 4 s\left({ }^{2} F\right) 4 p^{3} G^{\circ}$ \\
\hline 645100.0 & 645113 & -13 & 2 & $313 d^{9} 7 p{ }^{1} D^{\circ}+263 d^{8} 4 s\left({ }^{4} F\right) 4 p^{3} F^{\circ}+153 d^{9} 7 p^{3} P^{\circ}$ \\
\hline 645761.0 & 645779 & -18 & 2 & $313 d^{8} 4 s\left({ }^{4} F\right) 4 p^{3} F^{\circ}+283 d^{9} 7 p{ }^{1} D^{\circ}+153 d^{8} 4 s\left({ }^{2} F\right) 4 p{ }^{3} \mathrm{P}^{\circ}$ \\
\hline 649365.0 & 649363 & 2 & 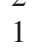 & $553 \mathrm{~d}^{9} 7 \mathrm{p}^{3} \mathrm{P}^{\circ}+443 \mathrm{~d}^{9} 7 \mathrm{p}^{1} \mathrm{P}^{\circ}$ \\
\hline 652760.0 & 652759 & 1 & 1 & $483 d^{9} 6 f^{3} D^{\circ}+443 d^{9} 6 f^{1} P^{\circ}+73 d^{9} 6 f^{3} P^{\circ}$ \\
\hline 657140.0 & 657136 & 4 & 1 & $533 \mathrm{~d}^{9} 6 \mathrm{f}^{1} \mathrm{P}^{\circ}+323 \mathrm{~d}^{9} 6 \mathrm{f}^{3} \mathrm{D}^{\circ}+143 \mathrm{~d}^{9} 6 \mathrm{f}^{3} \mathrm{P}^{\circ}$ \\
\hline 658225.0 & 658292 & -67 & 2 & $443 d^{8} 4 s\left({ }^{2} \mathrm{D}\right) 4 p^{1} D^{\circ}+293 d^{8} 4 s\left({ }^{4} P\right) 4 p{ }^{3} P^{\circ}+113 d^{8} 4 s\left({ }^{2} P\right) 4 p^{3} P^{\circ}$ \\
\hline 660117.0 & 660121 & -4 & 1 & $443 \mathrm{~d}^{8} 4 \mathrm{~s}\left({ }^{4} \mathrm{P}\right) 4 \mathrm{p}{ }^{3} \mathrm{P}^{\circ}+293 \mathrm{~d}^{8} 4 \mathrm{~s}\left({ }^{2} \mathrm{D}\right) 4 \mathrm{p}{ }^{1} \mathrm{P}^{\circ}+153 \mathrm{~d}^{8} 4 \mathrm{~s}\left({ }^{2} \mathrm{P}\right) 4 \mathrm{p}^{3} \mathrm{P}^{\circ}$ \\
\hline 662544.0 & 662506 & 38 & 0 & $713 \mathrm{~d}^{8} 4 \mathrm{~s}\left({ }^{4} \mathrm{P}\right) 4 \mathrm{p}^{3} \mathrm{P}^{\circ}+233 \mathrm{~d}^{8} 4 \mathrm{~s}\left({ }^{2} \mathrm{P}\right) 4 \mathrm{p}^{3} \mathrm{P}^{\circ}$ \\
\hline 662890.0 & 662996 & -106 & 2 & $373 d^{8} 4 s\left({ }^{2} D\right) 4 p{ }^{1} P^{\circ}+413 d^{8} 4 s\left({ }^{2} D\right) 4 p{ }^{1} D^{\circ}+153 d^{8} 4 s\left({ }^{2} P\right) 4 p{ }^{3} P^{\circ}$ \\
\hline 664749.0 & 664753 & -4 & 1 & $553 \mathrm{~d}^{8} 4 \mathrm{~s}\left({ }^{2} \mathrm{D}\right) 4 \mathrm{p}{ }^{1} \mathrm{P}^{\circ}+263 \mathrm{~d}^{8} 4 \mathrm{~s}\left({ }^{2} \mathrm{P}\right) 4 \mathrm{p}^{3} \mathrm{P}^{\circ}+93 \mathrm{~d}^{8} 4 \mathrm{~s}\left({ }^{2} \mathrm{P}\right) 4 \mathrm{p}^{3} \mathrm{P}^{\circ}$ \\
\hline 665937.0 & 665832 & 105 & 3 & $443 d^{8} 4 s\left({ }^{4} G\right) 4 p^{3} D^{\circ}+313 d^{8} 4 s\left({ }^{2} P\right) 4 p^{3} D^{\circ}+143 d^{8} 4 s\left({ }^{2} D\right) 4 p{ }^{1} F^{\circ}$ \\
\hline 672445.0 & 672521 & -76 & 3 & $873 d^{8} 4 s\left({ }^{2} \mathrm{G}\right) 4 p^{1} \mathrm{~F}^{\circ}+73 \mathrm{~d}^{8} 4 \mathrm{~s}\left({ }^{2} \mathrm{D}\right) 4 \mathrm{p}^{1} \mathrm{~F}^{\circ}$ \\
\hline 683090.0 & 683102 & -12 & 0 & $963 \mathrm{~d}^{8} 4 \mathrm{~s}\left({ }^{2} \mathrm{~S}\right) 4 \mathrm{p}^{3} \mathrm{P}^{\circ}$ \\
\hline 684337.0 & 684227 & 110 & 1 & $963 \mathrm{~d}^{8} 4 \mathrm{~s}\left({ }^{2} \mathrm{~S}\right) 4 \mathrm{p}^{3} \mathrm{P}^{\circ}$ \\
\hline 686617.0 & 686716 & -99 & 2 & $973 d^{8} 4 s\left({ }^{2} S\right) 4 p^{3} P^{\circ}$ \\
\hline
\end{tabular}


T. Rauch et al.: Stellar laboratories: new Ge V and Ge VI oscillator strengths

Table 3. Energy levels of Ge VI (in $\mathrm{cm}^{-1}$ ). The first three LS-components are given when they are over 5\%.

\begin{tabular}{|c|c|c|c|c|}
\hline$E_{\text {exp }}$ & $E_{\text {calc }}$ & $\Delta E$ & $J$ & LS-coupling composition (\%) \\
\hline 0.0 & 0 & 0 & 2.5 & $993 d^{9}{ }^{2} \mathrm{D}$ \\
\hline 4560.0 & 4560 & 0 & 1.5 & $993 d^{9}{ }^{2} \mathrm{D}$ \\
\hline 303696.2 & 303702 & -6 & 4.5 & $993 d^{8}\left({ }^{3} F\right) 4 s^{4} F$ \\
\hline 306243.4 & 306227 & 17 & 3.5 & $933 d^{8}\left({ }^{3} F\right) 4 s{ }^{4} F+73 d^{8}\left({ }^{3} F\right) 4 s{ }^{2} F$ \\
\hline 308657.2 & 308619 & 38 & 2.5 & $973 \mathrm{~d}^{8}\left({ }^{3} \mathrm{~F}\right) 4 \mathrm{~s}{ }^{4} \mathrm{~F}$ \\
\hline 310199.1 & 310149 & 50 & 1.5 & $973 d^{8}\left({ }^{3} F\right) 4 s^{4} F$ \\
\hline 313024.6 & 313083 & -59 & 3.5 & $933 d^{8}\left({ }^{3} F\right) 4 s^{2} F+73 d^{8}\left({ }^{3} F\right) 4 s{ }^{4} F$ \\
\hline 316936.8 & 316978 & -41 & 2.5 & $943 d^{8}\left({ }^{3} F\right) 4 s^{2} F$ \\
\hline 327537.9 & 327580 & -42 & 2.5 & $523 \mathrm{~d}^{8}\left({ }^{3} \mathrm{P}\right) 4 \mathrm{~s}^{4} \mathrm{P}+453 \mathrm{~d}^{8}\left({ }^{1} \mathrm{D}\right) 4 \mathrm{~s}^{2} \mathrm{D}$ \\
\hline 329073.6 & 328991 & 83 & 1.5 & $743 \mathrm{~d}^{8}\left({ }^{1} \mathrm{D}\right) 4 \mathrm{~s}^{2} \mathrm{D}+173 \mathrm{~d}^{8}\left({ }^{3} \mathrm{P}\right) 4 \mathrm{~s}{ }^{4} \mathrm{P}+73 \mathrm{~d}^{8}\left({ }^{3} \mathrm{P}\right) 4 \mathrm{~s}^{2} \mathrm{P}$ \\
\hline 332376.6 & 332399 & -22 & 1.5 & $823 \mathrm{~d}^{8}\left({ }^{3} \mathrm{P}\right) 4 \mathrm{~s}^{4} \mathrm{P}+173 \mathrm{~d}^{8}\left({ }^{1} \mathrm{D}\right) 4 \mathrm{~s}^{2} \mathrm{D}$ \\
\hline 332497.0 & 332529 & -32 & 0.5 & $993 d^{8}\left({ }^{3} \mathrm{P}\right) 4 \mathrm{~s}^{4} \mathrm{P}$ \\
\hline 333034.6 & 333108 & -73 & 2.5 & $503 \mathrm{~d}^{8}\left({ }^{1} \mathrm{D}\right) 4 \mathrm{~s}^{2} \mathrm{D}+483 \mathrm{~d}^{8}\left({ }^{3} \mathrm{P}\right) 4 \mathrm{~s}^{4} \mathrm{P}$ \\
\hline 339335.3 & 339356 & -21 & 1.5 & $923 d^{8}\left({ }^{3} P\right) 4 s^{2} P+73 d^{8}\left({ }^{1} D\right) 4 s^{2} D$ \\
\hline 340525.3 & 340418 & 107 & 0.5 & $993 d^{8}\left({ }^{3} \mathrm{P}\right) 4 \mathrm{~s}^{2} \mathrm{P}$ \\
\hline 343624.4 & 343641 & -16 & 4.5 & $993 \mathrm{~d}^{8}\left({ }^{1} \mathrm{G}\right) 4 \mathrm{~s}^{2} \mathrm{G}$ \\
\hline 343674.0 & 343658 & 16 & 3.5 & $993 \mathrm{~d}^{8}\left({ }^{1} \mathrm{G}\right) 4 \mathrm{~s}^{2} \mathrm{G}$ \\
\hline 391183.2 & 391183 & 0 & 0.5 & $993 d^{8}\left({ }^{1} S\right) 4 s^{2} S$ \\
\hline 404892.3 & 405152 & -260 & 3.5 & $873 d^{8}\left({ }^{3} F\right) 4 p^{4} D^{\circ}+63 d^{8}\left({ }^{3} F\right) 4 p^{4} F^{\circ}$ \\
\hline 408981.1 & 409123 & -142 & 2.5 & $853 d^{8}\left({ }^{3} F\right) 4 p^{4} D^{\circ}+73 d^{8}\left({ }^{3} F\right) 4 p^{4} F^{\circ}+63 d^{8}\left({ }^{3} P\right) 4 p^{4} D^{\circ}$ \\
\hline 409188.4 & 409218 & -30 & 4.5 & $563 d^{8}\left({ }^{3} F\right) 4 p^{4} G^{\circ}+253 d^{8}\left({ }^{3} F\right) 4 p^{2} G^{\circ}+183 d^{8}\left({ }^{3} F\right) 4 p^{4} F^{\circ}$ \\
\hline 411591.6 & 411314 & 278 & 5.5 & $993 d^{8}\left({ }^{3} F\right) 4 p^{4} G^{\circ}$ \\
\hline 411885.9 & 411737 & 149 & 3.5 & $763 d^{8}\left({ }^{3} F\right) 4 p{ }^{4} G^{\circ}+123 d^{8}\left({ }^{3} F\right) 4 p{ }^{4} F^{\circ}+93 d^{8}\left({ }^{3} F\right) 4 p^{2} G^{\circ}$ \\
\hline 412037.7 & 412098 & -60 & 1.5 & $873 d^{8}\left({ }^{3} F\right) 4 p{ }^{4} D^{\circ}+83 d^{8}\left({ }^{3} P\right) 4 p{ }^{4} D^{\circ}$ \\
\hline 413728.0 & 413500 & 228 & 2.5 & $883 d^{8}\left({ }^{3} F\right) 4 p^{4} G^{\circ}+73 d^{8}\left({ }^{3} F\right) 4 p^{4} F^{\circ}$ \\
\hline 413872.6 & 413887 & -14 & 0.5 & $893 d^{8}\left({ }^{3} F\right) 4 p^{4} D^{\circ}+103 d^{8}\left({ }^{3} P\right) 4 p{ }^{4} D^{\circ}$ \\
\hline 415142.7 & 415074 & 69 & 4.5 & $793 d^{8}\left({ }^{3} F\right) 4 p{ }^{4} F^{\circ}+143 d^{8}\left({ }^{3} F\right) 4 p^{2} G^{\circ}+73 d^{8}\left({ }^{3} F\right) 4 p{ }^{4} G^{\circ}$ \\
\hline 416709.7 & 416633 & 77 & 3.5 & $583 d^{8}\left({ }^{3} F\right) 4 p{ }^{4} F^{\circ}+253 d^{8}\left({ }^{3} F\right) 4 p^{2} F^{\circ}+93 d^{8}\left({ }^{3} F\right) 4 p^{4} G^{\circ}$ \\
\hline 417421.2 & 417416 & 5 & 4.5 & $613 d^{8}\left({ }^{3} F\right) 4 p^{2} G^{\circ}+373 d^{8}\left({ }^{3} F\right) 4 p^{4} G^{\circ}$ \\
\hline 417792.2 & 417828 & -36 & 1.5 & $643 d^{8}\left({ }^{3} F\right) 4 p{ }^{4} F^{\circ}+203 d^{8}\left({ }^{3} F\right) 4 p^{2} D^{\circ}+113 d^{8}\left({ }^{1} D\right) 4 p^{2} D^{\circ}$ \\
\hline 417941.9 & 417861 & 81 & 2.5 & $633 d^{8}\left({ }^{3} F\right) 4 p{ }^{4} F^{\circ}+193 d^{8}\left({ }^{3} F\right) 4 p{ }^{2} D^{\circ}+73 d^{8}\left({ }^{3} F\right) 4 p^{4} G^{\circ}$ \\
\hline 420117.8 & 420255 & -137 & 2.5 & $603 d^{8}\left({ }^{3} F\right) 4 p^{2} D^{\circ}+153 d^{8}\left({ }^{3} F\right) 4 p{ }^{2} F^{\circ}+133 d^{8}\left({ }^{3} F\right) 4 p{ }^{4} F^{\circ}$ \\
\hline 420542.0 & 420655 & -113 & 3.5 & $583 \mathrm{~d}^{8}\left({ }^{3} \mathrm{~F}\right) 4 \mathrm{p}^{2} \mathrm{~F}^{\circ}+213 \mathrm{~d}^{8}\left({ }^{3} \mathrm{~F}\right) 4 \mathrm{p}^{2} \mathrm{G}^{\circ}+193 \mathrm{~d}^{8}\left({ }^{3} \mathrm{~F}\right) 4 \mathrm{p}^{4} \mathrm{~F}^{\circ}$ \\
\hline 421310.0 & 421376 & -66 & 3.5 & $663 d^{8}\left({ }^{3} F\right) 4 p^{2} G^{\circ}+133 d^{8}\left({ }^{3} F\right) 4 p{ }^{2} F^{\circ}+133 d^{8}\left({ }^{3} F\right) 4 p{ }^{4} G^{\circ}$ \\
\hline 423030.0 & 423105 & -75 & 1.5 & $543 d^{8}\left({ }^{3} F\right) 4 p^{2} D^{\circ}+303 d^{8}\left({ }^{3} F\right) 4 p{ }^{4} F^{\circ}+93 d^{8}\left({ }^{1} D\right) 4 p^{2} D^{\circ}$ \\
\hline 424506.4 & 424513 & -7 & 2.5 & $743 d^{8}\left({ }^{3} F\right) 4 p{ }^{2} F^{\circ}+123 d^{8}\left({ }^{3} F\right) 4 p{ }^{2} D^{\circ}+93 d^{8}\left({ }^{3} F\right) 4 p{ }^{4} F^{\circ}$ \\
\hline 429997.3 & 430095 & -98 & 1.5 & $733 \mathrm{~d}^{8}\left({ }^{3} \mathrm{P}\right) 4 \mathrm{p}{ }^{4} \mathrm{P}^{\circ}+93 \mathrm{~d}^{8}\left({ }^{1} \mathrm{D}\right) 4 \mathrm{p}^{2} \mathrm{P}^{\circ}+83 \mathrm{~d}^{8}\left({ }^{3} \mathrm{~F}\right) 4 \mathrm{p}^{2} \mathrm{D}^{\circ}$ \\
\hline 430736.0 & 430846 & -110 & 2.5 & $653 \mathrm{~d}^{8}\left({ }^{3} \mathrm{P}\right) 4 \mathrm{p}^{4} \mathrm{P}^{\circ}+123 \mathrm{~d}^{8}\left({ }^{1} \mathrm{D}\right) 4 \mathrm{p}^{2} \mathrm{D}^{\circ}+113 \mathrm{~d}^{8}\left({ }^{1} \mathrm{D}\right) 4 \mathrm{p}^{2} \mathrm{~F}^{\circ}$ \\
\hline 431041.9 & 431094 & -52 & 0.5 & $913 \mathrm{~d}^{8}\left({ }^{3} \mathrm{P}\right) 4 \mathrm{p}{ }^{4} \mathrm{P}^{\circ}$ \\
\hline 433507.0 & 433438 & 69 & 2.5 & $693 d^{8}\left({ }^{1} \mathrm{D}\right) 4 \mathrm{p}^{2} \mathrm{~F}^{\circ}+203 \mathrm{~d}^{8}\left({ }^{3} \mathrm{P}\right) 4 \mathrm{p}^{4} \mathrm{P}^{\circ}$ \\
\hline 436023.6 & 436071 & -47 & 1.5 & $433 d^{8}\left({ }^{1} \mathrm{D}\right) 4 \mathrm{p}^{2} \mathrm{D}^{\circ}+183 \mathrm{~d}^{8}\left({ }^{3} \mathrm{P}\right) 4 \mathrm{p}^{4} \mathrm{P}^{\circ}+153 \mathrm{~d}^{8}\left({ }^{1} \mathrm{D}\right) 4 \mathrm{p}^{2} \mathrm{P}^{\circ}$ \\
\hline 436173.3 & 435966 & 207 & 3.5 & $713 d^{8}\left({ }^{1} \mathrm{D}\right) 4 p^{2} \mathrm{~F}^{\circ}+133 \mathrm{~d}^{8}\left({ }^{1} \mathrm{G}\right) 4 \mathrm{p}^{2} \mathrm{~F}^{\circ}+113 \mathrm{~d}^{8}\left({ }^{3} \mathrm{P}\right) 4 \mathrm{p}^{4} \mathrm{D}^{\circ}$ \\
\hline 436727.0 & 436699 & 28 & 0.5 & $603 \mathrm{~d}^{8}\left({ }^{1} \mathrm{D}\right) 4 \mathrm{p}^{2} \mathrm{P}^{\circ}+283 \mathrm{~d}^{8}\left({ }^{3} \mathrm{P}\right) 4 \mathrm{p}^{2} \mathrm{P}^{\circ}+73 \mathrm{~d}^{8}\left({ }^{3} \mathrm{P}\right) 4 \mathrm{p}^{4} \mathrm{P}^{\circ}$ \\
\hline 437801.0 & 437951 & -150 & 2.5 & $743 d^{8}\left({ }^{1} \mathrm{D}\right) 4 \mathrm{p}^{2} \mathrm{D}^{\circ}+83 \mathrm{~d}^{8}\left({ }^{3} \mathrm{P}\right) 4 \mathrm{p}^{4} \mathrm{P}^{\circ}+73 \mathrm{~d}^{8}\left({ }^{3} \mathrm{P}\right) 4 \mathrm{p}^{2} \mathrm{D}^{\circ}$ \\
\hline 438871.4 & 438918 & -46 & 1.5 & $493 \mathrm{~d}^{8}\left({ }^{1} \mathrm{D}\right) 4 \mathrm{p}^{2} \mathrm{P}^{\circ}+313 \mathrm{~d}^{8}\left({ }^{1} \mathrm{D}\right) 4 \mathrm{p}^{2} \mathrm{D}^{\circ}+63 \mathrm{~d}^{8}\left({ }^{3} \mathrm{P}\right) 4 \mathrm{p}^{2} \mathrm{P}^{\circ}$ \\
\hline 441221.0 & 441056 & 165 & 0.5 & $863 d^{8}\left({ }^{3} P\right) 4 p^{4} D^{\circ}+93 d^{8}\left({ }^{3} F\right) 4 p^{4} D^{\circ}$ \\
\hline 441278.0 & 441101 & 177 & 1.5 & $743 d^{8}\left({ }^{3} \mathrm{P}\right) 4 p^{4} \mathrm{D}^{\circ}+63 \mathrm{~d}^{8}\left({ }^{3} \mathrm{~F}\right) 4 \mathrm{p}^{4} \mathrm{D}^{\circ}+63 \mathrm{~d}^{8}\left({ }^{1} \mathrm{D}\right) 4 \mathrm{p}^{2} \mathrm{P}^{\circ}$ \\
\hline 441386.0 & 441368 & 18 & 2.5 & $603 d^{8}\left({ }^{3} \mathrm{P}\right) 4 \mathrm{p}^{4} \mathrm{D}^{\circ}+183 \mathrm{~d}^{8}\left({ }^{3} \mathrm{P}\right) 4 \mathrm{p}^{2} \mathrm{D}^{\circ}+63 \mathrm{~d}^{8}\left({ }^{1} \mathrm{D}\right) 4 \mathrm{p}^{2} \mathrm{~F}^{\circ}$ \\
\hline 442790.4 & 442667 & 123 & 3.5 & $763 \mathrm{~d}^{8}\left({ }^{3} \mathrm{P}\right) 4 \mathrm{p}^{4} \mathrm{D}^{\circ}+153 \mathrm{~d}^{8}\left({ }^{1} \mathrm{G}\right) 4 \mathrm{p}^{2} \mathrm{~F}^{\circ}$ \\
\hline 444442.2 & 444429 & 13 & 4.5 & $973 \mathrm{~d}^{8}\left({ }^{1} \mathrm{G}\right) 4 \mathrm{p}^{2} \mathrm{H}^{\circ}$ \\
\hline 445439.0 & 445313 & 126 & 1.5 & $743 d^{8}\left({ }^{3} \mathrm{P}\right) 4 \mathrm{p}^{2} \mathrm{P}^{\circ}+123 \mathrm{~d}^{8}\left({ }^{1} \mathrm{D}\right) 4 \mathrm{p}^{2} \mathrm{P}^{\circ}+73 \mathrm{~d}^{8}\left({ }^{3} \mathrm{P}\right) 4 \mathrm{p}^{2} \mathrm{D}^{\circ}$ \\
\hline 445670.0 & 445783 & -113 & 2.5 & $673 d^{8}\left({ }^{3} \mathrm{P}\right) 4 \mathrm{p}^{2} \mathrm{D}^{\circ}+253 \mathrm{~d}^{8}\left({ }^{3} \mathrm{P}\right) 4 \mathrm{p}^{4} \mathrm{D}^{\circ}$ \\
\hline 447373.0 & 447431 & -58 & 1.5 & $833 d^{8}\left({ }^{3} P\right) 4 p{ }^{2} D^{\circ}+93 d^{8}\left({ }^{3} P\right) 4 p{ }^{4} D^{\circ}$ \\
\hline 447780.0 & 447962 & -182 & 3.5 & $663 d^{8}\left({ }^{1} \mathrm{G}\right) 4 p^{2} \mathrm{~F}^{\circ}+213 \mathrm{~d}^{8}\left({ }^{1} \mathrm{D}\right) 4 \mathrm{p}^{2} \mathrm{~F}^{\circ}+73 \mathrm{~d}^{8}\left({ }^{3} \mathrm{P}\right) 4 \mathrm{p}^{4} \mathrm{D}^{\circ}$ \\
\hline 448258.9 & 448097 & 162 & 5.5 & $993 d^{8}\left({ }^{1} \mathrm{G}\right) 4 p^{2} \mathrm{H}^{\circ}$ \\
\hline 449093.0 & 448900 & 193 & 0.5 & $603 d^{8}\left({ }^{3} \mathrm{P}\right) 4 \mathrm{p}^{2} \mathrm{P}^{\circ}+233 \mathrm{~d}^{8}\left({ }^{1} \mathrm{D}\right) 4 \mathrm{p}^{2} \mathrm{P}^{\circ}+133 \mathrm{~d}^{8}\left({ }^{3} \mathrm{P}\right) 4 \mathrm{p}^{2} \mathrm{~S}^{\circ}$ \\
\hline 450153.0 & 450186 & -33 & 2.5 & $843 d^{8}\left({ }^{1} G\right) 4 p^{2} F^{\circ}+83 d^{8}\left({ }^{1} D\right) 4 p^{2} F^{\circ}$ \\
\hline 451362.0 & 451604 & -242 & 0.5 & $843 d^{8}\left({ }^{3} \mathrm{P}\right) 4 \mathrm{p}^{2} \mathrm{~S}^{\circ}+83 \mathrm{~d}^{8}\left({ }^{1} \mathrm{D}\right) 4 \mathrm{p}^{2} \mathrm{P}^{\circ}+63 \mathrm{~d}^{8}\left({ }^{3} \mathrm{P}\right) 4 \mathrm{p}^{2} \mathrm{P}^{\circ}$ \\
\hline 451501.0 & 451538 & -37 & 1.5 & $963 d^{8}\left({ }^{3} P\right) 4 p^{4} S^{\circ}$ \\
\hline 458378.0 & 458402 & -24 & 3.5 & $963 \mathrm{~d}^{8}\left({ }^{1} \mathrm{G}\right) 4 \mathrm{p}^{2} \mathrm{G}^{\circ}$ \\
\hline 459014.5 & 459053 & -39 & 4.5 & $973 \mathrm{~d}^{8}\left({ }^{1} \mathrm{G}\right) 4 \mathrm{p}^{2} \mathrm{G}^{\circ}$ \\
\hline 496179.5 & 496213 & -33 & 0.5 & $973 \mathrm{~d}^{8}\left({ }^{1} \mathrm{~S}\right) 4 \mathrm{p}^{2} \mathrm{P}^{\circ}$ \\
\hline 500575.3 & 500541 & 34 & 1.5 & $973 \mathrm{~d}^{8}\left({ }^{1} \mathrm{~S}\right) 4 \mathrm{p}^{2} \mathrm{P}^{\circ}$ \\
\hline
\end{tabular}

